\title{
THE BEAUTY CONTEST AND SHORT-TERM TRADING
}

\author{
Giovanni Cespa \\ Xavier Vives
}


The Public-Private Sector Research Center is a Research Center based at IESE Business School. Its mission is to develop research that analyses the relationships between the private and public sectors primarily in the following areas: regulation and competition, innovation, regional economy and industrial politics and health economics.

Research results are disseminated through publications, conferences and colloquia. These activities are aimed to foster cooperation between the private sector and public administrations, as well as the exchange of ideas and initiatives.

The sponsors of the Public-Private Sector Research Center are the following:

- Ajuntament de Barcelona

- Departament d' Economia i Coneixement de la Generalitat de Catalunya

- Departament d' Empresa i Ocupació de la Generalitat de Catalunya

- Diputació de Barcelona

- Fundació AGBAR

- Institut Català de les Empreses Culturals (ICEC)

- PricewaterhouseCoopers

- Sanofi

- FGC

The contents of this publication reflect the conclusions and findings of the individual authors, and not the opinions of the Center's sponsors. 


\title{
THE BEAUTY CONTEST AND SHORT-TERM TRADING*
}

\author{
Giovanni Cespa ${ }^{\dagger}$ and Xavier Vives ${ }^{\ddagger}$
}

January 2014

\begin{abstract}
We consider a two-period market with persistent liquidity trading and risk averse privately informed investors who have a one period horizon. With persistence, prices reflect average expectations about fundamentals and liquidity trading. Informed investors engage in "retrospective" learning to reassess the inference about fundamentals made at the early stage of the trading game. This introduces strategic complementarities in the use of information and can yield two stable equilibria which can be ranked in terms of liquidity, volatility, and informational efficiency. We establish the limits of the beauty contest analogy for financial markets and derive a rich set of implications to explain market anomalies, and empirical regularities.

Keywords: Price speculation, multiple equilibria, average expectations, public information, momentum and reversal, Beauty Contest.
\end{abstract}

JEL Classification Numbers: G10, G12, G14

*A previous version of this paper was circulated under the title "Higher Order Expectations, Illiquidity, and Short-term Trading." We thank the Co-Editor (Bruno Biais), the Associate Editor, and two anonymous referees, as well as Elias Albagli, Max Bruche, Giacinta Cestone, Hans Degryse, Marcelo Fernandes, Itay Goldstein, Peter Hoffmann, Harrison Hong, Peter Kondor, Jean-Paul Laurent, Olivier Loisel, Stephen Morris, Richard Payne, Ioanid Roşu, Kristien Smedts, Gunther Wuyts, Kathy Yuan, Liyan Yang, and seminar participants in the Econometrics Workshop at Queen Mary University of London, ESSEC, Paris Dauphine, Paris SciencesPo, Amsterdam (joint Finance seminar series of Duisenberg School of Finance and Tinbergen Institute), Leuven, MIT Sloan, LSE, City University London, the IESEG workshop on Asset Pricing, the 2010 EFA meeting (Frankfurt), the ELSE-UCL Workshop in Financial Economics (UCL, September 2010), the 2011 ESSET (Gerzensee), the 2011 SED meeting (Gent), the CNMV conference on "Securities Markets: The Crisis and the Challenges Ahead," (Madrid, November 2011), the 2012 EEA meeting (Málaga), the 6th Financial Risks International Forum (Paris, March 2013), the Barcelona GSE Summer Forum on "Information, Competition, and Market Frictions" for their comments. Cespa acknowledges financial support from ESRC (grant n. ES/J00250X/1). Vives acknowledges financial support from the European Research Council under the Advanced Grant project Information and Competition (no. 230254) and from project ECO2011-29533 of the Spanish Ministry of Science and Innovation at the Public-Private Sector Research Center at IESE.

${ }^{\dagger}$ Cass Business School, City University London, CSEF, and CEPR. 106, Bunhill Row, London EC1Y 8TZ, UK. e-mail: giovanni.cespa@gmail.com

${ }^{\ddagger}$ IESE Business School, Avinguda Pearson, 2108034 Barcelona, Spain. 


\section{Introduction}

We study the drivers of asset prices in a two-period market where short-term, informed, competitive, risk-averse agents trade on account of private information and to accommodate liquidity supply, facing a persistent demand from liquidity traders.

Traders' "myopia" ranks high on the regulatory agenda testifying policy makers' concern with the possibly detrimental impact it has on the market 1$]$ The issue has a long tradition in economic analysis. Indeed, short term trading is at the base of Keynes' dismal view of financial markets. According to Keynes' "Beauty Contest," traders' investment decisions are driven by the anticipation of their peers' changing whims, rather than by the actual knowledge of the companies they trade. In this context it has been claimed that this type of behavior introduces a particular form of informational inefficiency, whereby traders tend to put a disproportionately high weight on public information in their forecast of asset prices (see Allen, Morris, and Shin (2006)).

In this paper we present a two-period model of short term trading with asymmetric information in the tradition of dynamic noisy rational expectations models (see, e.g., Singleton (1987), Brown and Jennings (1989)). We find that when liquidity trading is persistent there is strategic complementarity in the use of private information and provide sufficient conditions for it to be strong enough to generate multiple and stable equilibria which can be ranked in terms of price informativeness, liquidity, and volatility; this allows us to establish the limits of the beauty contest analogy for financial markets, and deliver sharp predictions on asset pricing which are consistent with the received empirical evidence (including noted anomalies).

Suppose a risk-averse, short term trader has a private signal on the firm's fundamentals. His willingness to speculate on such signal is directly related to how much of his information will be reflected in the price at which he liquidates. However, and importantly, it is also inversely related to his uncertainty about such a price. Indeed, the more

\footnotetext{
${ }^{1}$ While the market presence of institutional investors, a class of investors traditionally considered as being long termists, has steadily increased in the last two decades, their holding period has sensibly decreased. According to the OECD (see http://www.oecd.org/daf/fin/financial-markets/48616812. pdf), ". . . the average holding period [of institutional investors] has fallen between one and three years in selected OECD stock exchanges over the last twenty years. Looking further back, the drop is even greater. For instance, in the 1980s, the average holding period in the New York stock exchange was over 5 years, compared to 5 months today." In a recent policy paper, Haldane and Davies (2011) look at a large panel of UK and US listed companies over the period 1980-2009, and uncover compelling evidence of a short term investor bias which has worsened in the last 10 years of the sample. According to their findings, due to myopic behavior a 5-year ahead cash flow ends up being discounted at a rate that would better suit a 8-year ahead cash flow, while for 10- or 30-year ahead cash flows the effect is even more dramatic.
} 
volatile the price at which he unwinds, the riskier his strategy, and the less willing to exploit his private signal the trader becomes. But in a market with asymmetric information, a reduced response to private information can feed back in the volatility of the price. This is because, the less information is transmitted to the price, the larger is the contribution of non-fundamentals trades to price volatility. Therefore, the willingness to act on private information depends on the trader's uncertainty over the liquidation price, and at the same time affects such uncertainty. In this paper we show that this two-sided loop can be responsible for the existence of multiple, stable equilibria that can be ranked in terms of informational efficiency, liquidity, and volatility.

The crux of our argument revolves around a particular type of inference effect from the information reflected by prices that arises when liquidity traders' positions are correlated across trading dates. Indeed, with persistence second period investors can retrospectively reassess the first period inference about the fundamentals, based on the new evidence gathered in the second period. We thus term this effect "retrospective inference." In a market with risk averse, asymmetrically informed investors, it is well-known that the price impact of trades arises from the sum of an "inventory" component, and an "inference" component ${ }^{2}$ While in a static market the two terms are positive, in a dynamic market retrospective inference can make the inference component turn negative. This diminishes the price impact of trades, reducing the volatility of the asset price, and boosting traders' response to private information. The intuition is as follows.

Suppose that second period informed investors observe a large demand for the asset. If in the first period investors traded aggressively (weakly) on their private information, the first period price is very (poorly) informative about the fundamentals, but poorly (very) informative about liquidity traders' demand. However, to price the asset risk averse investors also need to correctly estimate the demand of liquidity traders (the fundamentals). Suppose they attribute the high demand realization to liquidity traders (informed investors). With persistence, this implies that a high demand for the asset from liquidity traders (informed investors) also affected the first period aggregate demand. But for a given price realization, this implies a lower (higher) expectation of the fundamentals. Thus, in this case a large aggregate demand realization leads second period investors to revise down (up) their expectation of the liquidation value. This, in turn, implies that the inference component of the price impact offsets (reinforces) the inventory component

\footnotetext{
${ }^{2}$ The former captures the price variation due to the the change in asset exposure investors experience when clearing the market; the latter captures the price change due to the inference investors make from the aggregate demand for the asset.
} 
making the latter small (large). This diminishes (increases) first period investors' uncertainty over the price at which they unwind, boosting (lowering) their response to private signals.

We show that when the retrospective inference loop is present but not too strong, two stable equilibria arise. In one equilibrium (which we call the "High" Information Equilibrium, HIE) prices are very good signals of the underlying fundamentals, volatility is low, and liquidity is high. The other equilibrium, (which we call the "Low" Information Equilibrium, LIE), displays instead opposite properties in terms of informational efficiency, volatility, and liquidity. Thus, a first contribution of our paper is to refute the view that short term trading always amplifies demand shocks or is necessarily conducive to poorly informative prices, and "excess" volatility $]^{3}$ When instead the retrospective inference loop is very strong, the HIE becomes unstable, so that the only likely equilibrium to arise is the LIE.

Our analysis shows that the strength of the retrospective inference loop depends on traders' reliance on prices as a source of information for their decisions. For example, when private signals are very precise compared to exogenous public information, prices are more informative, the loop is strong, and the HIE is unstable. When the public signal precision increases, the loop weakens, making the HIE stable. Finally, when public information increases further, the HIE disappears, and uniqueness occurs at the LIE. Thus, our paper shows that public information can have an active role in selecting equilibria in a market with short term trading.

Along the HIE, the inference component of liquidity is negative. As explained above, this finding is due to second period traders revising downwards their first period assessment of the payoff in the presence of a positive demand shock, because of retrospective inference. Interestingly, this finding has an empirical counterpart, as some spread decomponsition models find that, consistently with the prediction of the HIE, the inference component of the spread can be negative 4 Thus, our model provides a theoretical justification for this empirical finding, relating it to the informational efficiency of asset

\footnotetext{
${ }^{3}$ Part of the debate on the consequences of short term trading revolves precisely around the alleged negative impact it has on the informativeness of asset prices (see, e.g., the recently published "Kay review of UK equity markets and long term decision making," available at http://lawcommission.justice. gov.uk/docs/kay-review-of-equity-markets-final-report.pdf).

${ }^{4}$ See for instance Huang and Stoll (1997), Van Ness, Van Ness, and Warr (2001), and Henker and Wang (2006). Hamm (2010) investigates the effect of ETFs on the liquidity of underlying stocks and estimates a spread decomposition model based on Madhavan, Richardson, and Roomans (1997). In several of her findings the inference component of the spread is negative, which leads to the exclusion of such "out-of-range" observations.
} 
prices.

Our paper also shows that in the HIE the autocovariance of short-term returns is always positive, while along the LIE this only occurs when liquidity trading is sufficiently persistent. Given that liquidity trading predictability is an essential ingredient of equilibrium multiplicity, momentum is thus due to persistence. However, the patterns of prices and price informativeness implied by the two equilibria are markedly different. In particular, momentum along the HIE (LIE) is a sign that prices are rapidly (slowly) converging towards the full information value. Together with our finding on the sign of the inference component of liquidity, this offers a way to empirically discriminate across the two equilibria.

Finally, our paper shows that the informational properties related to the beauty contest nature of prices depend on the equilibrium that arises. Along the LIE, we find that traders put a high weight on public information. However, along the HIE traders overweight aggregate (and noisy) private information. This enables us to qualify the results obtained by Allen, Morris, and Shin (2006).

The rest of the paper is organized as follows. In the next section we discuss the literature related to our paper. We then analyze the static benchmark. In section 4 , we study the two-period model and present the multiplicity result, relating it to liquidity traders' persistence. In the following sections we relate our results to the literature on Higher Order Expectations and derive asset pricing implications. The final section summarizes our results and discusses their empirical implications. Most of the proofs are relegated to the appendix.

\section{Related literature}

Our results are related to and have implications for three strands of the literature.

First, our paper is related to the literature that investigates the relationship between the impact of short-term investment horizons on prices and investors' reaction to their private signals (see, e.g. Singleton (1987), Brown and Jennings (1989), Froot, Scharfstein, and Stein (1992), Dow and Gorton (1994), Vives (1995), Cespa (2002), Albagli (2011) and Vives (2008) for a survey). If prices are semi-strong efficient (as in Vives (1995)) traders do not require a compensation to increase their exposure to the asset (and the inventory component of the price impact disappears). As a consequence, the retrospective inference loop breaks down, and a unique equilibrium obtains. Brown and Jennings (1989), instead analyze a model in which prices are not semi-strong efficient, with short 
term investors and where liquidity trading can be correlated. Their work provides a rationale for "technical analysis," showing how in the absence of semi-strong efficiency the sequence of transaction prices provides more information than the current stock price to forecast the final payoff. We argue that lacking semi-strong efficiency, in the presence of correlated liquidity trading, second period investors can retrospectively evaluate the inference made in the first period, which generates strategic complementarities in the use of private information, and potentially yields multiple equilibria.

Other authors find that in the presence of short-term traders multiple equilibria can arise. In this respect, part of the literature assumes an infinite horizon economy. In this case, multiplicity arises out of the bootstrap nature of expectations in the steady state equilibrium of an overlapping generations model with two-period lived investors. Spiegel (1998) studies the model with symmetric information 5 Watanabe (2008) extends the model of Spiegel (1998) to account for the possibility that investors have heterogeneous short-lived private information $\sqrt{6}$ Other authors instead generate multiple equilibria in finite horizon economies. Zhang (2012) shows that short-term trading generates multiple equilibria that can be ranked in terms of price informativeness. However, multiplicity there arises at the information acquisition stage, while we find multiplicity in the response to private information. Furthermore, public information in the low information equilibrium crowds out the production of private information, which is the opposite of what happens in our case. Similarly, Avdis (2012) also finds that short-term trading can generate multiple equilibria in information acquisition. Finally, Chen, Huang, and Zhang (2012) analyze a model with short-term trading and in which traders receive signals of different precisions. They show that with transient liquidity trading, multiple equilibria in the response to private information can arise. Some of the effects in their model contrast with ours. In particular, one of their finding is that when public precision is high (low), improved public information improves (lowers) price informativeness. This effect does not arise in our model.

Second, the paper is related to the work that studies the influence of Higher Order Expectations (HOEs) on asset prices (see Allen, Morris, and Shin (2006), Bacchetta and

\begin{tabular}{l}
\hline${ }^{5}$ Assuming the absence of private information, our model is akin to a finite horizon version of Spiegel \\
\hline$(1998)$ and it is possible to show that in this case a unique equilibrium obtains. \\
\hline \hline${ }^{6}$ In his case too the analysis concentrates on the steady state equilibrium, which does not make his \\
\hline results directly comparable to ours. Furthermore, in Watanabe (2008) fundamentals information is \\
\hline short lived, whereas in our model it is long lived, which substantially changes the nature of the inference \\
problem faced by first period investors. Relatedly,|Dennert (1991) studies an OLG extension of Grossman \\
and Stiglitz (1980), concentrating on the steady state solution. In his setup too private information is \\
short-lived. \\
\hline
\end{tabular}


van Wincoop (2008), Kondor (2012), and Nimark (2007)). Allen, Morris, and Shin (2006) find, in a model identical to ours but with transient liquidity trading, that when prices are driven by HOEs about fundamentals, they underweight private information (with respect to the optimal statistical weight) and are farther away from fundamentals compared to consensus. We show that in the unique equilibrium that obtains when liquidity trading is transient, investors dampen their response to private information and this result holds. A similar result also holds when liquidity trading is persistent, in the LIE. However, along the HIE the price is more strongly tied to fundamentals compared to consensus, and overweights average private information (compared to the optimal statistical weight).7 Therefore, the beauty contest feature of asset prices does not necessarily imply that prices are worse estimators of fundamentals compared to consensus, nor that they exhibit inertia or react slowly to changes in the fundamentals. Bacchetta and van Wincoop (2006) study the role of HOEs in the FX market. They show that HOEs worsen the signal extraction problem that investors face when observing changes in the exchange rate that originate from trades based on fundamentals information and hedging motives. In our setup this happens in the LIE, whereas in the HIE, investors' strong reaction to private information eases off the signal extraction problem.

Finally, the paper is also related to the literature on limits to arbitrage. In this respect, our multiplicity result is reminiscent of De Long et al. (1990), but in a model with rational traders, and a finite horizon. Thus, our paper naturally relates to the strand of this literature that views limits to arbitrage as the analysis of how "non-fundamental demand shocks" impact asset prices in models with rational agents (Gromb and Vayanos (2010), Vayanos and Woolley (2013)). Our contribution in this respect is twofold: first, we prove that when such shocks display persistence, they impact in a non-trivial way the information extraction process of rational investors, generating implications for price efficiency and market liquidity. Second, we relate these findings to the literature on return predictability. In fact, along the HIE, we show that momentum arises at short horizons, while at long horizons reversal occurs in any equilibrium. Our model also predicts that momentum is related to a high volume of informational trading, in line with the evidence in Llorente, Michaely, Saar, and Wang (2002).

\footnotetext{
${ }^{7}$ In a related paper, we show that a similar conclusion holds in a model with long term investors (see Cespa and Vives (2012)).
} 


\section{The static benchmark}

Consider a one-period stock market where a single risky asset with liquidation value $v$, and a risk-less asset with unitary return are traded by a continuum of risk-averse, informed investors in the interval $[0,1]$ together with liquidity traders. We assume that $v \sim N\left(\bar{v}, \tau_{v}^{-1}\right)$. Investors have CARA preferences (denote by $\gamma$ the risk-tolerance coefficient) and maximize the expected utility of their wealth: $W_{i}=(v-p) x_{i}{ }^{8}$ Prior to the opening of the market every informed investor $i$ obtains private information on $v$, receiving a signal $s_{i}=v+\epsilon_{i}, \epsilon_{i} \sim N\left(0, \tau_{\epsilon}^{-1}\right)$, and submits a demand schedule (generalized limit order) to the market $X\left(s_{i}, p\right)$ indicating the desired position in the risky asset for each realization of the equilibrium price..$^{9}$ Assume that $v$ and $\epsilon_{i}$ are independent for all $i$, and that error terms are also independent across investors. Liquidity traders submit a random demand $u$ (independent of all other random variables in the model), where $u \sim N\left(0, \tau_{u}^{-1}\right)$. Finally, we make the convention that, given $v$, the average signal $\int_{0}^{1} s_{i} d i$ equals $v$ almost surely (i.e. errors cancel out in the aggregate: $\left.\int_{0}^{1} \epsilon_{i} d i=0\right){ }^{10}$

In the above CARA-normal framework, a symmetric rational expectations equilibrium (REE) is a set of trades contingent on the information that investors have, $\left\{X\left(s_{i}, p\right)\right.$ for $i \in$ $[0,1]\}$ and a price functional $P(v, u)$ (measurable in $(v, u)$ ), such that investors in $[0,1]$ optimize given their information and the market clears:

$$
\int_{0}^{1} x_{i} d i+u=0
$$

Given the above definition, it is easy to verify that a unique, symmetric equilibrium in linear strategies exists in the class of equilibria with a price functional of the form $P(v, u)$ (see, e.g. Admati (1985), Vives (2008)). The equilibrium strategy of an investor $i$ is given by

$$
X\left(s_{i}, p\right)=\frac{a}{\alpha_{E}}\left(E\left[v \mid s_{i}, p\right]-p\right)
$$

where

$$
a=\gamma \tau_{\epsilon}
$$

denotes the responsiveness to private information, $\left.\tau_{i} \equiv\left(\operatorname{Var}\left[v \mid s_{i}, p\right]\right]\right)^{-1}$, and $\alpha_{E}=\tau_{\epsilon} / \tau_{i}$ is the optimal statistical (Bayesian) weight to private information. Imposing market

\footnotetext{
${ }^{8}$ We assume, without loss of generality with CARA preferences, that the non-random endowment of informed investors is zero.

${ }^{9}$ The unique equilibrium in linear strategies of this model is symmetric.

${ }^{10}$ See Section 3.1 in the Technical Appendix of Vives (2008) for a justification of the convention.
} 
clearing the equilibrium price is given by

$$
\begin{aligned}
p & =\int_{0}^{1} E_{i}[v] d i+\frac{\alpha_{E}}{a} u \\
& =E[v \mid p]+\Lambda E[u \mid p]
\end{aligned}
$$

where $E[u \mid p]=a(v-E[v \mid p])+u$, and

$$
\Lambda=\frac{\operatorname{Var}_{i}[v]}{\gamma}
$$

Equations (2), and (3) show that the price can be given two alternative representations. According to the first one, the price reflects the consensus opinion investors hold about the liquidation value plus the impact of the demand from liquidity traders (multiplied by the risk-tolerance weighted uncertainty over the liquidation value). Indeed, in a static market owing to CARA and normality, an investor's demand is proportional to the expected gains from trade $E\left[v \mid s_{i}, p\right]-p$. As the price aggregates all investors' demands, it reflects the consensus opinion $\int_{0}^{1} E_{i}[v] d i$ shocked by the orders of liquidity traders.

According to (3), the equilibrium price reflects investors' estimates of the fundamentals $v$ (the "semi-strong" efficient price $E[v \mid p]$ ) and of liquidity traders' demand $u$. Indeed, risk averse investors demand a compensation to accommodate liquidity traders' orders. With differential information, these are not perfectly observable from the price. Hence, such a compensation is increasing in investors' estimate $E[u \mid p]$ scaled by $\Lambda$. In view of (4), for a given $E[u \mid p]$, the higher is investors' uncertainty about the liquidation value or their risk aversion, the higher is $\Lambda$, and the higher is this compensation. Therefore, $\Lambda$ captures the "inventory" component of market liquidity.11 Liquidity traders' orders have an additional effect on the price, through their impact on the semi-strong efficient price $E[v \mid p]$. This effect induces an inference component which adds to the inventory component, implying that the (reciprocal of the) liquidity of the market is measured by:

$$
\lambda \equiv \frac{\partial p}{\partial u}=\Lambda+\left(1-\alpha_{E}\right) \frac{a \tau_{u}}{\tau},
$$

\footnotetext{
${ }^{11}$ When risk averse investors accommodate an expectedly positive demand of liquidity traders, they require a compensation against the possibility that the liquidation value is higher than the public expectation (if instead $E[u \mid p]<0$, investors require to pay a price lower than $E[v \mid p]$ to cover the risk that $v<E[v \mid p]$ ). Such a compensation is larger, the higher is the uncertainty investors face (captured by $\Lambda$ ) and the wider is their expected exposure to the liquidity traders' shock (their expected inventory, $E[u \mid p])$.
} 
where $\tau=1 / \operatorname{Var}[v \mid p]=\tau_{v}+a^{2} \tau_{u} \sqrt{12}$ Note that other things equal, in a static setup the inference component magnifies the price impact of liquidity traders' orders.

\section{A two-period market with short term investors}

Consider now a two-period extension of the market analyzed in the previous section. At date 1 (2), a continuum of short-term investors in the interval $[0,1]$ enters the market, loads a position in the risky asset which it unwinds in period 2 (3). Investor $i$ has CARA preferences (denote by $\gamma$ the common risk-tolerance coefficient) and maximizes the expected utility of his short term profit $\pi_{i n}=\left(p_{n+1}-p_{n}\right) x_{i n}, n=1,2$ (with $p_{0}=\bar{v}$ and $\left.p_{3}=v\right){ }^{13}$ The short term horizons of investors can be justified on grounds of incentive reasons related to performance evaluation, or because of difficulties associated with financing long-term investment in the presence of capital market imperfections (see Holmström and Ricart i Costa (1986), and Shleifer and Vishny (1990)). An investor $i$ who enters the market in period 1 receives a signal $s_{i}=v+\epsilon_{i}$ which he recalls in the second period, where $\epsilon_{i} \sim N\left(0, \tau_{\epsilon}^{-1}\right), v$ and $\epsilon_{i}$ are independent for all $i$. Furthermore, we assume that in the second period a signal $s_{P}=v+\eta$ is publicly disclosed to the market, where $\eta \sim N\left(0, \tau_{\eta}^{-1}\right)$ is independent of $v$ and $\epsilon_{i}$ for all $i$. We make the convention that, given $v$, the average private signal $\int_{0}^{1} s_{i} d i$ equals $v$ almost surely (i.e., errors cancel out in the aggregate $\left.\int_{0}^{1} \epsilon_{i} d i=0\right)$.

We restrict attention to equilibria in linear demand functions, and denote by $X_{1}\left(s_{i}, p_{1}\right)=$ $a_{1} s_{i}-\varphi_{1}\left(p_{1}\right)$, and $X_{2}\left(s_{i}, s_{P}, p_{1}, p_{2}\right)=a_{2} s_{i}+b s_{P}-\varphi_{2}\left(p_{1}, p_{2}\right)$ an investor's desired position in the risky asset for each realization of the equilibrium price at dates 1 and 2 . The constants $a_{n}$, and $b$ respectively denote an investor's weight to private information at date $n$ and his weight to the public signal. The function $\varphi_{n}(\cdot)$ is a linear function of the equilibrium prices. ${ }^{14}$

The position of liquidity traders is assumed to follow an $\mathrm{AR}(1)$ process:

$$
\begin{gathered}
\theta_{1}=u_{1} \\
\theta_{2}=\beta \theta_{1}+u_{2},
\end{gathered}
$$

\footnotetext{
${ }^{12}$ The adverse selection effect comes from the signal extraction problem dealers face in this market: since $a>0$, if investors on average have good news they buy the asset, and $E[v \mid p]$ increases, reflecting this information. However, this effect cannot be told apart from the buying pressure of liquidity traders, which also makes $E[v \mid p]$ increase.

${ }^{13}$ We assume, without loss of generality, that the non-random endowment of investors is zero.

${ }^{14}$ The equilibria in linear strategies of this model are symmetric.
} 
where $\beta \in[0,1]$ and $\left\{u_{1}, u_{2}\right\}$ is an i.i.d. normally distributed random process (independent of all other random variables in the model) with $u_{n} \sim N\left(0, \tau_{u}^{-1}\right)$. Other authors have adopted this assumption for liquidity traders, among which Singleton (1987), Campbell and Kyle (1993), He and Wang (1995), Biais, Bossaerts, and Spatt (2010) and Cespa and Vives (2012). If $\beta=1,\left\{\theta_{1}, \theta_{2}\right\}$ follows a random walk and we are in the usual case of independent liquidity trade increments: $u_{2}=\theta_{2}-\theta_{1}$ is independent from $u_{1}$ (e.g., Kyle (1985), Vives (1995)). If $\beta=0$, then liquidity trading is i.i.d. across periods (this is the case considered by Allen et al. (2006)).

Persistence in liquidity trading can be given several possible interpretations, depending on the frequency of observations. First, at a daily or intra-daily frequency, assuming persistence is a simple way to capture the need of liquidity traders to break down a large order in a series of smaller orders to minimize price impact, and is consistent with several empirical findings (e.g., Griffin, Harris, and Topaloglu (2003), and Chordia and Subrahmanyam (2004)). Next, Coval and Stafford (2007) show that mutual funds faced with aggregate redemption orders engage in "fire sales," (and purchases) creating a contemporaneous, uninformed, temporary negative (positive) price pressure ${ }^{15}$ Coupling this with the evidence documenting that capital flows to and from mutual funds are strongly related to past performance (see, e.g. Chevalier and Ellison (1997), Sirri and Tufano (1998)), negative shocks to mutual funds' capital can affect funds' trades yielding a negative (positive) impact on their performance, and feeding back to the funds' capital outflows (inflows). Thus, at a lower frequency, liquidity trading persistence can be seen as a reduced form assumption for the effect of the performance-flow relationship on mutual funds' holdings. ${ }^{16}$ Finally, note that while persistent liquidity trading is taken as a primitive of the model, it can be shown to arise endogenously in a model in which liquidity traders are replaced by rational hedgers with different investment horizons (see Cespa and Vives (2013)).17

\footnotetext{
${ }^{15}$ More in detail, Coval and Stafford (2007) argue that "fire sales" occur in mutual funds following specialized investment strategies and with significant overlap in their holdings.

${ }^{16}$ Evidence of such a source of persistence is provided by Lou (2012), who finds that the funds' flow induced trades are highly persistent at a quarterly frequency.

${ }^{17}$ More specifically, suppose that we replace the first period liquidity traders with a set of hedgers in the interval $[0,1]$, each of whom receives an idiosyncratic, normally distributed endowment shock $\theta_{i 1}$ (independent from the other random variables of the model). All hedgers take a position in the asset at date 0 . However, a fraction $\beta$ of them (denoted by HL) have a "long term" horizon, and hold such position until the liquidation date; the complementary fraction (denoted by HS) has a "short term" horizon, and liquidates the position at date 2 . In this model it can be shown that, in a linear equilibrium, persistence corresponds to the $\beta$-weighted relative responsiveness to the endowment shock displayed by HL. As hedgers' responsiveness are endogenous, with asymmetric information this introduces a participation externality (similar to the one in Pagano (1989), Admati and Pfleiderer (1988), and Dow (2005)) where hedgers decisions to trade in the first period depend on market liquidity, which in turn also depends on
} 
We denote by $E_{i 1}[Y]=E\left[Y \mid s_{i}, p_{1}\right], \operatorname{Var}_{i 1}[Y]=\operatorname{Var}\left[Y \mid s_{i}, p_{1}\right], E_{1}[Y]=E\left[Y \mid p_{1}\right]$, and $\operatorname{Var}_{1}[Y]=\operatorname{Var}\left[Y \mid p_{1}\right]$, respectively the expectation and variance of the random variable $Y$ formed by a date 1 investor using private and public information, and only public information. Similar definitions for date 2 investors yield $E_{i 2}[Y]=E\left[Y \mid s_{i}, s_{P}, p_{1}, p_{2}\right]$, $\operatorname{Var}_{i 2}[Y]=\operatorname{Var}\left[Y \mid s_{i}, s_{P}, p_{1}, p_{2}\right], E_{2}[Y]=E\left[Y \mid s_{P}, p_{1}, p_{2}\right]$, and $\operatorname{Var}_{2}[Y]=\operatorname{Var}\left[Y \mid s_{P}, p_{1}, p_{2}\right]$. The variables $\tau_{n}$ and $\tau_{\text {in }}$ denote the precisions of the investors' forecasts of $v$ based only on public and on public and private information: $\tau_{n}=\left(1 / \operatorname{Var}_{n}[v]\right)$, and $\tau_{\text {in }}=\left(1 / \operatorname{Var}_{i n}[v]\right)$. Letting $\alpha_{E_{n}}=\tau_{\epsilon} / \tau_{\text {in }}$, we have $E_{i n}[v]=\alpha_{E_{n}} s_{i n}+\left(1-\alpha_{E_{n}}\right) E_{n}[v]$.

\subsection{Equilibrium pricing and restrospective inference}

We start by giving a general description of the equilibrium. The following proposition characterises equilibrium prices:

Proposition 1. At a linear equilibrium:

1. The price is given by

$$
p_{n}=\alpha_{P_{n}}\left(v+\frac{\theta_{n}}{a_{n}}\right)+\left(1-\alpha_{P_{n}}\right) E_{n}[v]
$$

where $\theta_{n}=u_{n}+\beta \theta_{n-1}$, and $a_{n}, \alpha_{P_{n}}$ denote, respectively, the responsiveness to private information displayed by investors and by the price at period $n$ (see expressions A.5a, A.5b, A.10, and A.11). We have that $\alpha_{P_{2}}=\alpha_{E_{2}}<1$.

2. Let $\Delta a_{2}=a_{2}-\beta a_{1}$, and denote by $z_{1} \equiv a_{1} v+\theta_{1}, z_{2} \equiv \Delta a_{2} v+u_{2}$ the noisy informational additions about $v$ generated by informed investors, respectively in period 1 and 2 . Then $z_{1}$ is observationally equivalent (o.e.) to $p_{1}$, and given $s_{P}$, $\left\{z_{1}, z_{2}\right\}$ is o.e. to $\left\{p_{1}, p_{2}\right\}$.

According to (6), at period $n$ the equilibrium price is a weighted average of the market expectation about the fundamentals $v$, and the (noisy) average private information held by investors. Rearranging this expression yields

$$
\begin{aligned}
p_{n}-E_{n}[v] & =\frac{\alpha_{P_{n}}}{a_{n}}\left(a_{n}\left(v-E_{n}[v]\right)+\theta_{n}\right) \\
& =\Lambda_{n} E_{n}\left[\theta_{n}\right],
\end{aligned}
$$

hedgers' decision to trade. This introduces a new loop that can generate multiplicity with different levels of hedging activity. 
where $\Lambda_{n} \equiv \alpha_{P_{n}} / a_{n}$, implying that there is a discrepancy between $p_{n}$ and $E_{n}[v]$ which, as in the static market (see (3p), captures a premium which is proportional to the expected stock of liquidity trading that investors accommodate at $n$ :

Corollary 1. At a linear equilibrium, the price incorporates a premium above the semistrong efficient price:

$$
p_{n}=E_{n}[v]+\Lambda_{n} E_{n}\left[\theta_{n}\right]
$$

where $\Lambda_{2}=\operatorname{Var}_{i 2}[v] / \gamma$, and

$$
\Lambda_{1}=\frac{\operatorname{Var}_{i 1}\left[p_{2}\right]}{\gamma}+\beta \Lambda_{2}
$$

Comparing (9) with (4) shows that short term trading affects the inventory component of liquidity. In a static market when investors absorb the demand of liquidity traders, they are exposed to the risk coming from the randomness of $v$. In a dynamic market, short term investors at date 1 face instead the risk due to the randomness of the following period price (at which they unwind). As liquidity trading displays persistence, second period informed investors absorb part of first period liquidity traders' position and this contributes to first period investors' uncertainty over $p_{2}$, yielding (9).

As in the static benchmark, besides the impact of the inventory component $\Lambda_{n}$, with differential information the price impact also reflects an inference component as the following corollary shows:

Corollary 2. Let $a_{0}=0$. At a linear equilibrium,

$$
\begin{gathered}
p_{1}=\lambda_{1} z_{1}+\left(1-\lambda_{1} a_{1}\right) \bar{v} \\
p_{2}=\lambda_{2} z_{2}+\frac{\tau_{\eta}}{\tau_{i 2}} s_{P}+\frac{\gamma \tau_{1} E_{1}[v]+\beta z_{1}}{\gamma \tau_{i 2}}
\end{gathered}
$$

where $\lambda_{n}$ denotes the price impact of trades in period $n=1,2$ and is given by:

$$
\lambda_{n} \equiv \frac{\partial p_{n}}{\partial u_{n}}=\frac{\alpha_{P_{n}}}{a_{n}}+\left(1-\alpha_{P_{n}}\right) \frac{\Delta a_{n} \tau_{u}}{\tau_{n}}
$$

According to (11) the inference component of liquidity at $n=2$ is captured by

$$
\left(1-\alpha_{P_{2}}\right) \frac{\Delta a_{2} \tau_{u}}{\tau_{2}}
$$

Differently from the static benchmark, in a dynamic market the sign of this component 
depends on the $\beta$-weighted net position of informed investors yielding net trading intensity $\Delta a_{2}=a_{2}-\beta a_{1}$. Indeed, denoting by $x_{n}=\int_{0}^{1} x_{i n} d i, n=1,2$, market clearing implies that:

$$
x_{1}+\theta_{1}=0, \text { and } x_{2}+\beta \theta_{1}+u_{2}=0 \Longrightarrow x_{2}-\beta x_{1}+u_{2}=0 .
$$

As a result, the impact of private information in the second period depends on the change in informed investors' position as measured by $\Delta a_{2}=a_{2}-\beta a_{1}$. This implies that the sign of the inference component depends on the relative magnitude of $a_{1}$ compared to $a_{2} / \beta{ }^{18}$ Therefore, the first period response to private information affects the informational innovation extracted from $p_{1}$ and, when $\beta>0$, also the one extracted from $p_{2}$ (that is, $z_{1}$, and $z_{2}$ ), as well as the sign of the inference component in $\lambda_{2}$.

At the same time, due to short horizons $a_{1}$ depends on the impact of new fundamentals information in the second period. This is because short term investors in the first period trade according to

$$
X_{1}\left(s_{i}, p_{1}\right)=\gamma \frac{E_{i 1}\left[p_{2}\right]-p_{1}}{\operatorname{Var}_{i 1}\left[p_{2}\right]} \Longrightarrow a_{1}=\gamma \frac{\text { Weight to } s_{i} \text { in } E_{i 1}\left[p_{2}\right]}{\operatorname{Var}_{i 1}\left[p_{2}\right]}
$$

The above expression implies that $a_{1}$ is directly related to the relevance of the private signal to forecast $p_{2}$, and inversely related to investors' uncertainty about $p_{2}$. Indeed, a private signal which is more informative about $p_{2}$ heightens investors' confidence in their forecast of the price at which they liquidate. On the other hand, when investors are more risk tolerant, or face lower uncertainty about $p_{2}$, they bear less the risk of an adverse price movement in the second period. Both effects thus lead investors to respond more aggressively to their private signal. Note in particular, that for any public signal realization, the extent to which $p_{2}$ differs from $p_{1}$ depends on $\lambda_{2}$ (see $(10 \mathrm{~b})$ ). This implies that a larger value for $\lambda_{2}$, other things equal, increases first period investors' uncertainty over $p_{2}$.

Summarizing, the first period response to private information depends on the impact of new information in $p_{2}$, but at the same time it also affects such impact through its effect on $z_{2}$ and $\lambda_{2}$. This two-sided loop gives rise to strategic complementarities in the use of private information, which can yield multiple equilibria. The crux of our argument revolves around a particular type of inference effect from the information reflected by prices that arises when $\beta>0$. When liquidity trading displays persistence, second period investors can retrospectively reassess the first period inference about the fundamentals,

\footnotetext{
${ }^{18}$ In the appendix we show that $\alpha_{P_{2}}=\alpha_{E_{2}}$, so that $1-\alpha_{P_{2}} \in(0,1)$.
} 
based on the new evidence gathered in the second period. We thus term this effect "retrospective inference."

Suppose that second period informed investors observe a large demand for the asset (i.e., $z_{2}$ high). If $a_{1}$ is very high (small), the first period price is very (poorly) informative about $v$, but poorly (very) informative about $\theta_{1}$ (since $z_{1}=a_{1} v+\theta_{1}$ ). However, to price the asset investors need to correctly estimate $\theta_{2}(v)$ (see (8)). Suppose they attribute the high demand realization to liquidity traders (informed investors). As $\beta>0$, this implies that a high demand for the asset from liquidity traders (informed investors) also affected the first period aggregate demand. But for a given price realization $p_{1}$, this implies a lower (higher) expectation of the fundamentals (in this respect, retrospective inference plays the same role of the "adverse fundamental" effect in Goldstein and Yang (2012)).19 Thus, in this case a large aggregate demand realization leads second period investors to revise down (up) their expectation of the liquidation value. This, in turn, implies that the inference component in $\lambda_{2}$ offsets (reinforces) the inventory component. As a consequence, the second period price impact of trade is small (large), which diminishes (increases) first period investors' uncertainty over $p_{2}$, boosting (lowering) their response to private signals 20

Consistent with the above intuition, we obtain the following result:

Proposition 2. Suppose $\tau_{\eta}>0$.

- If $\beta>1 / 2, \gamma^{2} \tau_{\epsilon} \tau_{u}>2(2 \beta-1) /(3-2 \beta)$, and $\tau_{\eta} \leq \hat{\tau}_{\eta}$ (for some $\hat{\tau}_{\eta}>0$ defined in the appendix, see (A.15c), there always exist at least three linear equilibria where $a_{2}=\gamma \tau_{\epsilon}$ and $a_{1} \in\left\{a_{1}^{*}, a_{1}^{* *}, a_{1}^{* * *}\right\}$, with $a_{1}^{*} \in\left(0, a_{2}\right)$,

$$
a_{1}^{* *} \in\left(\frac{1+\gamma \tau_{u} a_{2}}{\gamma \beta \tau_{u}}, \frac{2+3 \gamma \tau_{u} a_{2}}{2 \gamma \beta \tau_{u}}\right), a_{1}^{* * *}>\frac{2+3 \gamma \tau_{u} a_{2}}{2 \gamma \beta \tau_{u}}
$$

implying $a_{1}^{*}<a_{2}<a_{1}^{* *}<a_{1}^{* * *}$. When

$$
a_{1}=\left\{\begin{array}{ccr}
a_{1}^{*}, & \text { then } a_{2}-\beta a_{1}^{*}>0, \quad \text { and } \quad \lambda_{2}^{*}>0, \\
a_{1}^{* *}, a_{1}^{* * *}, \quad \text { then } & a_{2}-\beta a_{1}^{* *}<0, & \text { and } \quad \lambda_{2}^{* *}<0 .
\end{array}\right.
$$

\footnotetext{
${ }^{19}$ This is because, for given $p_{1}$ and $z_{1}=a_{1} v+\theta_{1}$, a higher value for $\theta_{1}$ provides stronger evidence that the fundamentals $v$ is low.

${ }^{20}$ See Ganguli and Yang (2009), and Avdis (2012) for complementarities in information acquisition in related models.
} 
Along these equilibria:

$$
\tau_{n}^{*}<\tau_{n}^{* *}<\tau_{n}^{* * *}, n=1,2 .
$$

- If $\beta=0$, there exists a unique equilibrium with $a_{2}=\gamma \tau_{\epsilon}$,

$$
\frac{\gamma^{2} a_{2} \tau_{u}\left(a_{2}^{2} \tau_{u}+\tau_{\epsilon}+\tau_{\eta}\right)}{1+\gamma^{2} \tau_{u}\left(a_{2}^{2} \tau_{u}+2 \tau_{\epsilon}+\tau_{\eta}\right)}<a_{1}^{*}<a_{2},
$$

and $\lambda_{2}^{*}>0$.

According to the above proposition, multiplicity requires that private information is strongly reflected in prices $\left(\gamma^{2} \tau_{\epsilon} \tau_{u}\right.$ large), persistence $(\beta)$ is high, and public precision $\left(\tau_{\eta}\right)$ is low. All of these conditions strengthen the retrospective inference loop. In view of (15) we refer to the three equilibria described in the Proposition as the Low, Intermediate, and High information equilibrium (LIE, IIE, and HIE). In the appendix we show that the first period equilibrium responsiveness obtains as a fixed point of the following function

$$
\psi\left(a_{1}\right)=\gamma \frac{\left(\lambda_{2} \Delta a_{2}+\tau_{\eta} / \tau_{i 2}\right) \alpha_{E_{1}}}{\left(\lambda_{2} \Delta a_{2}+\tau_{\eta} / \tau_{i 2}\right)^{2} / \tau_{i 1}+\lambda_{2}^{2} / \tau_{u}+\tau_{\eta} / \tau_{i 2}^{2}} .
$$

Numerical analysis shows that this function crosses the 45-degree line at most three times, suggesting the three equilibria described in Proposition 2 are the only ones that can arise (see Figure 1). Our numerical results further show that these equilibria can also be ranked in terms of second period price impact $\left(\lambda_{2}\right)$, inventory component of liquidity $\left(\Lambda_{n}\right)$, and conditional volatility $\left(\operatorname{Var}_{1}\left[p_{2}\right]\right)$. More in detail, we have

Numerical Result 1. When multiple equilibria arise

$$
\begin{gathered}
\lambda_{2}^{*}>\left|\lambda_{2}^{* *}\right|>\left|\lambda_{2}^{* * *}\right| \\
\Lambda_{n}^{*}>\Lambda_{n}^{* *}>\Lambda_{n}^{* * *} \\
\operatorname{Var}_{1}\left[p_{2}\right]^{*}>\operatorname{Var}_{1}\left[p_{2}\right]^{* *}>\operatorname{Var}_{1}\left[p_{2}\right]^{* * *} .
\end{gathered}
$$

Along the HIE, $\Delta a_{2}<0$, and the inference component of liquidity is negative. This finding is consistent with second period traders revising downwards their first period assessment of the payoff in the presence of a positive demand shock, due to retrospective inference. This result is also consistent with the findings of some spread decomponsition models (see for instance Huang and Stoll (1997), Van Ness, Van Ness, and Warr (2001), 


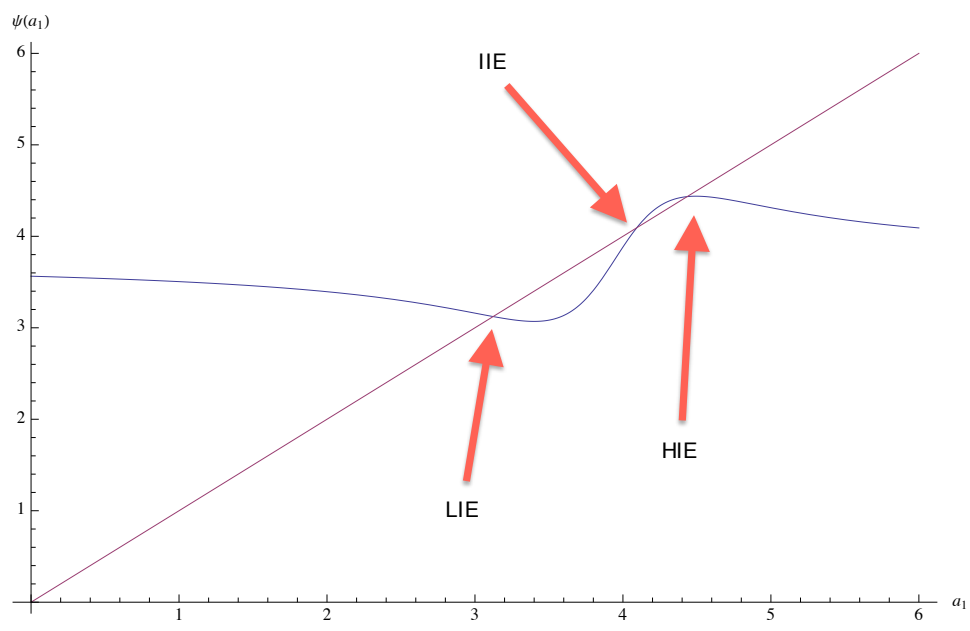

Figure 1: The best response mapping (16), for $\beta=1, \gamma=1 / 2, \tau_{u}=\tau_{v}=10, \tau_{\eta}=3$, and $\tau_{\epsilon}=7.5$.

and Henker and Wang (2006) $){ }^{21}$ Thus, our model provides a theoretical justification for this empirical finding.

In Figure 2 we display the effects of a change in the values of public and private signal precision, persistence, and liquidity traders' demand precision on the best response (16) ${ }^{22}$ As the figures show, uniqueness always obtains at the LIE and requires high public precision, or low private precision, persistence, or liquidity traders' precision. Intuitively, in all of these cases the endogenous public signal (the price) becomes relatively less informative than the exogenous public signal $\left(s_{P}\right)$, and second period investors rely less on price information. This weakens the self-reinforcing loop due to retrospective inference, yielding a unique equilibrium.

In Figure 3 we show that the effect of an increase in public signal precision on $a_{1}$ depends on the equilibrium that arises. Along the HIE (LIE), a larger $\tau_{\eta}$ leads to a reduction (increase) in $a_{1}$. The reason for this non-monotonicity is that a more precise

\footnotetext{
${ }^{21}$ Interestingly, in Huang and Stoll (1997) the assumption is made that market orders are generated by an $\mathrm{AR}(1)$ process, and the estimated parameter of such process turns out to be positive and close to 1. Negative inference components also occur with different spread decomposition models. For example, Hamm (2010) investigates the effect of ETFs on the liquidity of underlying stocks and estimates a spread decomposition model based on Madhavan, Richardson, and Roomans (1997). In several of her findings the inference component of the spread is negative, which leads to the exclusion of such "out-of-range" observations. See also Foucault, Pagano, and Roöell (2013), Ch. 5.2.2.

${ }^{22} \mathrm{Ex}$-ante public precision has little effect on the equilibrium, while the degree of risk tolerance has an effect similar to the one of private precision.
} 


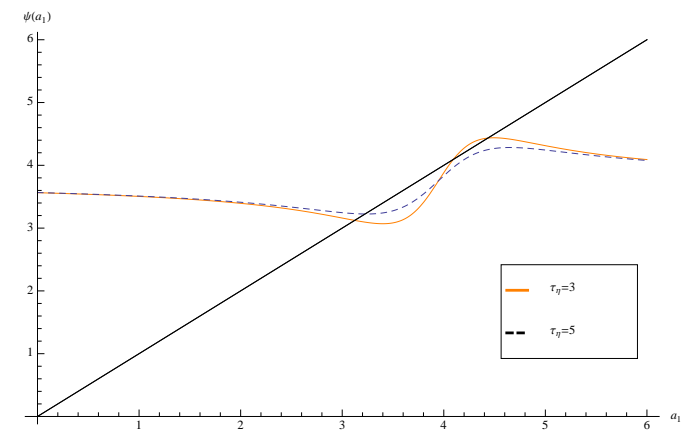

(a)

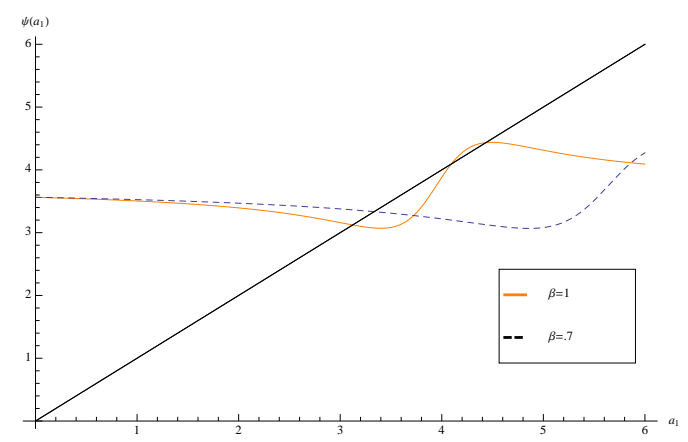

(c)

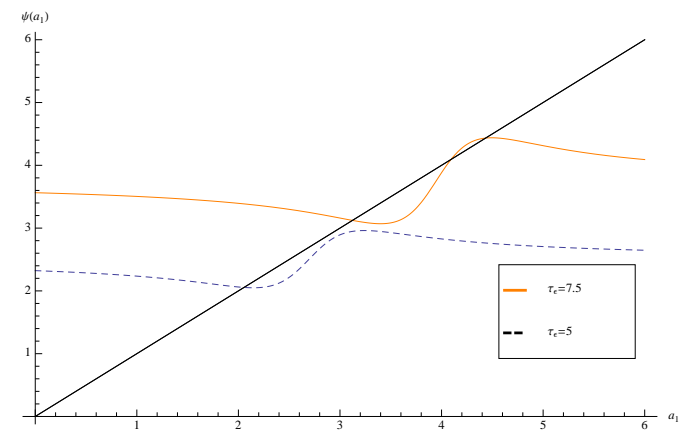

(b)

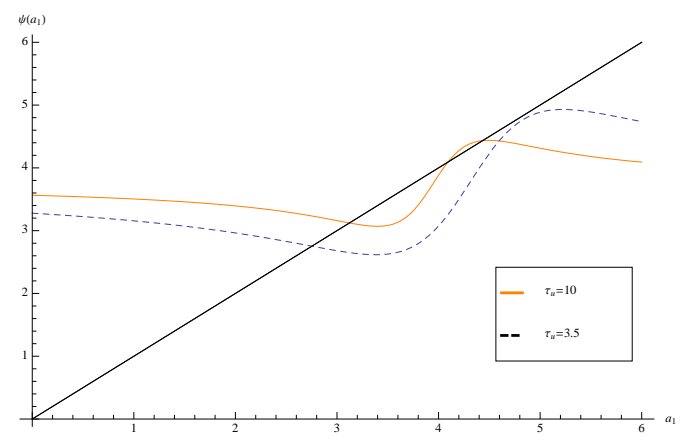

(d)

Figure 2: Comparative statics. We plot the best response $(16)$ for the parameters' value of Figure 1 (in orange) and show the effect of a change in the values of $\tau_{\eta}, \tau_{\epsilon}, \beta$, and $\tau_{u}$ (dashed, blue curve). More in detail, in panel (a) we increase public signal precision to $\tau_{\eta}=5$, in panel (b) we decrease private signal precision to $\tau_{\epsilon}=5$, in panel (c) we decrease liquidity traders' persistence to $\beta=.7$, and in panel (d) we decrease the precision of liquidity traders' demand to $\tau_{u}=3.5$.

public signal reduces traders' reliance on price information to forecast the fundamentals. Thus, along both equilibria the effect of retrospective inference is weaker in the second period. In the HIE (LIE) this increases (decreases) first period investors' uncertainty about $p_{2}$, leading to a decrease (increase) in $a_{1}{ }^{23}$

When the public signal is totally uninformative, for $\beta>0$, the retrospective inference loop becomes extremely strong. In this case, the best response (16) becomes discontinuous at the IIE (which therefore disappears, see Figure 3), and we always obtain two equilibria which can be computed in closed form:

\footnotetext{
${ }^{23}$ Along the HIE, second period investors faced with a large positive demand for the asset correct downwards their estimate of the fundamentals, which implies that the inference component of $\lambda_{2}$ is negative. Other things equal, a more precise public signal reduces the absolute value of the inference component, which works to increase first period investors' uncertainty about $p_{2}$. In the LIE, the opposite
} 


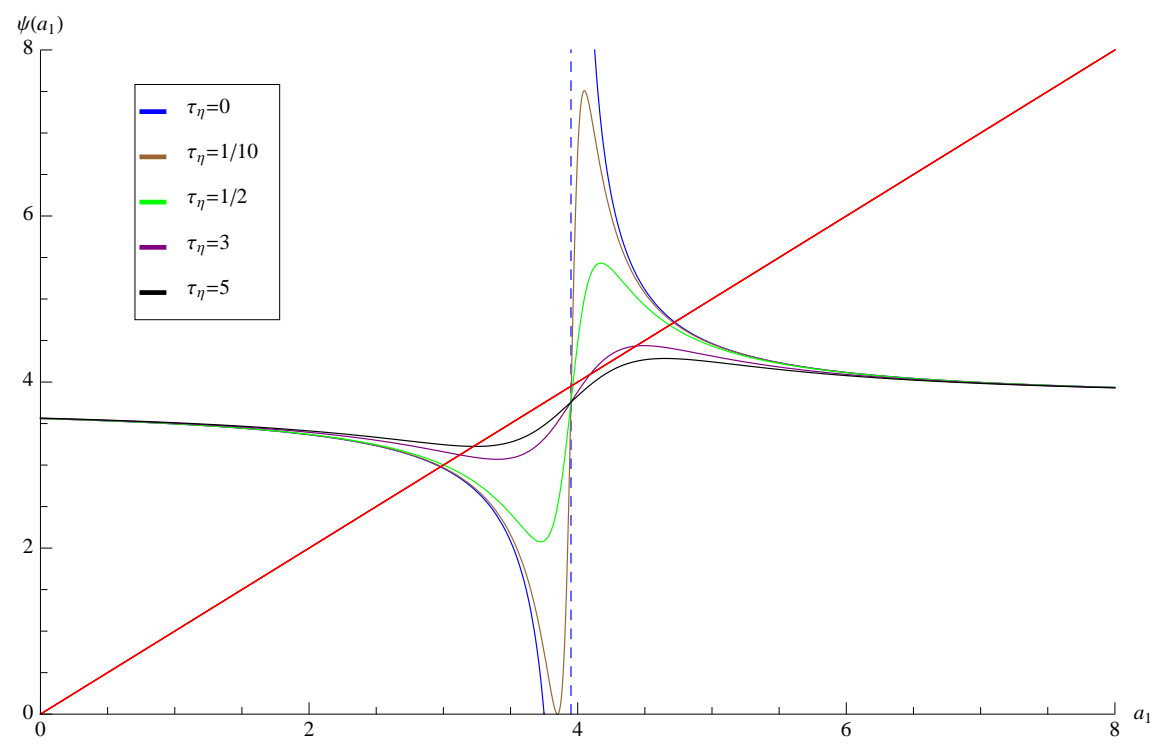

Figure 3: The best response mapping (16) when the public signal's precision ranges in the set $\{0,1 / 10,1 / 2,3,5\}$. Other parameters' values $\beta=1, \gamma=1 / 2, \tau_{u}=\tau_{v}=10, \tau_{\epsilon}=7.5$ and $\tau_{\eta}=0$. Note that when $\tau_{\eta}=0, \psi\left(\cdot, \tau_{\eta}\right)$ diverges at the point $\hat{a}_{1} \equiv\left(1+\gamma \tau_{u} a_{2}\right) /\left(\gamma \beta \tau_{u}\right)$, and the IIE disappears. For $\tau_{\eta}>0$, we have $\psi\left(\hat{a}_{1}, .1\right)=3.75864, \psi\left(\hat{a}_{1}, .5\right)=3.75862$, $\psi\left(\hat{a}_{1}, 3\right)=3.7585$, and $\psi\left(\hat{a}_{1}, 5\right)=3.7584$.

Corollary 3. Suppose $\tau_{\eta}=0$.

- If $\beta>0$, there always exist two linear equilibria where $a_{2}=\gamma \tau_{\epsilon}$, and $a_{1} \in\left\{a_{1}^{*}, a_{1}^{* * *}\right\}$, with $a_{1}^{*}<a_{2}<a_{1}^{* * *}$ (see (A.19), and A.20, in the appendix for explicit expressions). When

$$
a_{1}=\left\{\begin{array}{cccc}
a_{1}^{*}, & \text { then } \quad a_{2}-\beta a_{1}^{*}>0, & \text { and } \quad \lambda_{2}^{*}>0, & (L I E) \\
a_{1}^{* * *}, & \text { then } a_{2}-\beta a_{1}^{* * *}<0, & \text { and } \lambda_{2}^{* * *}<0, & \text { (HIE) } .
\end{array}\right.
$$

Furthermore, $\left|\lambda_{2}^{* * *}\right|<\lambda_{2}^{*}, \Lambda_{n}^{* * *}<\Lambda_{n}^{*}$, prices are more informative, and $\operatorname{Var}_{1}\left[p_{2}\right]$ is lower along the HIE.

- If $\beta=0$, there exists a unique equilibrium with $a_{2}=\gamma \tau_{\epsilon}$,

$$
a_{1}^{*}=\frac{\gamma a_{2}^{2} \tau_{u}}{1+\gamma a_{2} \tau_{u}}<a_{2}
$$

occurs. 
Remark 1. We can draw a parallel between our model and the models with a feedback effect of actions of investors to the value of the asset. In those papers (e.g, Ozdenoren and Yuan (2008), Bond, Goldstein, and Prescott (2010), Dow, Goldstein, and Guembel (2011), Goldstein, Ozdenoren, and Yuan (2013)) multiplicity of equilibria driven by complementarities also arises due to the impact of the price on the value of the asset. In our paper the price at $n=2, p_{2}$ represents the value of the asset from the perspective of investors at $n=1$ and their trading does affect $p_{2}$. This corresponds to the feedback effect from prices to values in the one-period feedback model. In Bond, Goldstein, and Prescott (2010) it is shown that if agents use market prices when deciding on corrective actions (say the board considers firing the CEO when the price of the stock is low), prices adjust to reflect this use and potentially become less revealing. In Ozdenoren and Yuan (2008), prices are informative about both the fundamentals and the likelihood of coordination among informed investors. Multiplicity occurs then when the price is more informative of the coordination motive rather than fundamentals. In this paper, the strength of the feedback effect depends on the sensitivity of the asset value to the investment in the risky asset. The parallel in our model is the degree of persistence in liquidity trading. Multiplicity tends to arise in both cases when the strength of the feedback effect is large. Similarly as in our model, multiplicity arises also when the precision of private information is high and base liquidity trading low. However, differently from Ozdenoren and Yuan (2008), where an increase in public precision leads to a higher coordination motive and multiple equilibria, in our model with no coordination motive, the result is the opposite.

\subsubsection{Stability}

In this section we use the best response (16) to perform a stability analysis of the equilibria. To analyze the stability of equilibrium, consider the following argument. Assume that the market is at an equilibrium point $\bar{a}_{1}$, so that $\bar{a}_{1}=\psi\left(\bar{a}_{1}\right)$. Suppose now that a small perturbation to $\bar{a}_{1}$ occurs. As a consequence, first period investors modify their weights to private information so that the aggregate weight becomes $\bar{a}_{1}^{\prime}=\psi\left(\bar{a}_{1}^{\prime}\right)$. If the market goes back to the original $\bar{a}_{1}$ according to the best reply dynamics with the best response function $\psi(\cdot)$, then the equilibrium is stable. Otherwise it is unstable. Thus, in a stable (unstable) equilibrium if investors other than $i$ put a lower weight on their signals then the price is noisier and investor $i$ reacts by increasing less (more) than proportionally the weight on his signal and contributing less (more) than proportionally to 
restore price informativeness. Formally, we have the following definition:

Definition 1 (Stability). An equilibrium is stable (unstable) if and only if its corresponding value for $a_{1}$ is a stable (unstable) fixed point for the best response function $\psi(\cdot)$ (i.e., if and only if its corresponding value for $a_{1}$ satisfies $\left.\left|\psi^{\prime}\left(a_{1}\right)<1\right|\right)$.

When $\tau_{\eta}>0$, if multiple equilbria arise the IIE is always unstable ${ }^{24}$ On the contrary, in our simulations the LIE is always stable. Finally, the behavior of the HIE is more complex. More in detail, for the HIE to be stable, we require private signals not to be "too" precise compared to the public signal. Indeed, in the extreme case when $\tau_{\eta}=0$, we can formally analyze the best response mapping and obtain the following result:

Corollary 4. When $\tau_{\eta}=0$, (i) $\psi^{\prime}\left(a_{1}\right)<0$, and (ii) the LIE (HIE) is stable (unstable) with respect to the best response dynamics:

$$
\left|\psi^{\prime}\left(a_{1}^{* * *}\right)\right|>1>\left|\psi^{\prime}\left(a_{1}^{*}\right)\right|
$$

Intuitively, when private information is much more precise than public information, the retrospective inference loop becomes very strong, and we approach a situation close to that described in Corollary 3, which makes the HIE always unstable.

In Figure 4 we set $\beta=1, \gamma=1 / 2, \tau_{u}=\tau_{v}=10$, and partition the parameter space $\left\{\tau_{\epsilon} \times \tau_{\eta} \mid \tau_{\eta} \in\{0, .01, \ldots, 10\}, \tau_{\epsilon} \in\{.01, .02, \ldots, 10\}\right\}$ into 5 regions, depending on whether a unique equilibrium or multiple equilibria (ME) obtain, whether the HIE is stable, and whether the response to private information are strategic substitutes or strategic complements (SS or SC) 25

Remark 2. It is possible to show that when prices are set by a sector of competitive, risk-neutral market makers, a unique equilibrium arises (as in Vives (1995)). Indeed, in this case market makers do not require an inventory-risk related compensation to clear

\footnotetext{
${ }^{24}$ This follows immediately from the fact that $\psi(0)>0$, so that the best response mapping cuts the 45-degree line from below at the IIE, implying that $\psi^{\prime}\left(a_{1}^{* *}\right)>1$.

${ }^{25}$ As shown in Figure 4, depending on parameters' values traders' responses to private information in the HIE and the LIE can be strategic complements or strategic substitutes. For given $\tau_{\epsilon}$, the higher is $\tau_{\eta}$, the more likely it is that one of the two equilibria displays strategic complementarities. For instance, for $\beta=1, \gamma=1 / 2, \tau_{u}=\tau_{v}=10, \tau_{\epsilon}=8$, and $\tau_{\eta}=2.5$, we obtain $\left(a_{1}^{*}, a_{1}^{* * *}\right)=(3.32,4.8)$, and $\left(\psi^{\prime}\left(a_{1}^{*}\right), \psi^{\prime}\left(a_{1}^{* * *}\right)\right)=(-0.4,-0.23)$. If we increase $\tau_{\eta}$ to 3 , we obtain $\left(a_{1}^{*}, a_{1}^{* * *}\right)=(3.34,4.73)$, and $\left(\psi^{\prime}\left(a_{1}^{*}\right), \psi^{\prime}\left(a_{1}^{* * *}\right)\right)=(-0.32,0.03)$. Finally, if we further increase $\tau_{\eta}$ to 5 (8), the HIE disappears and we obtain $a_{1}^{*}=3.44\left(a_{1}^{*}=3.59\right)$, with $\psi^{\prime}\left(a_{1}^{*}\right)=-0.05\left(\psi^{\prime}\left(a_{1}^{*}\right)=0.25\right)$.
} 


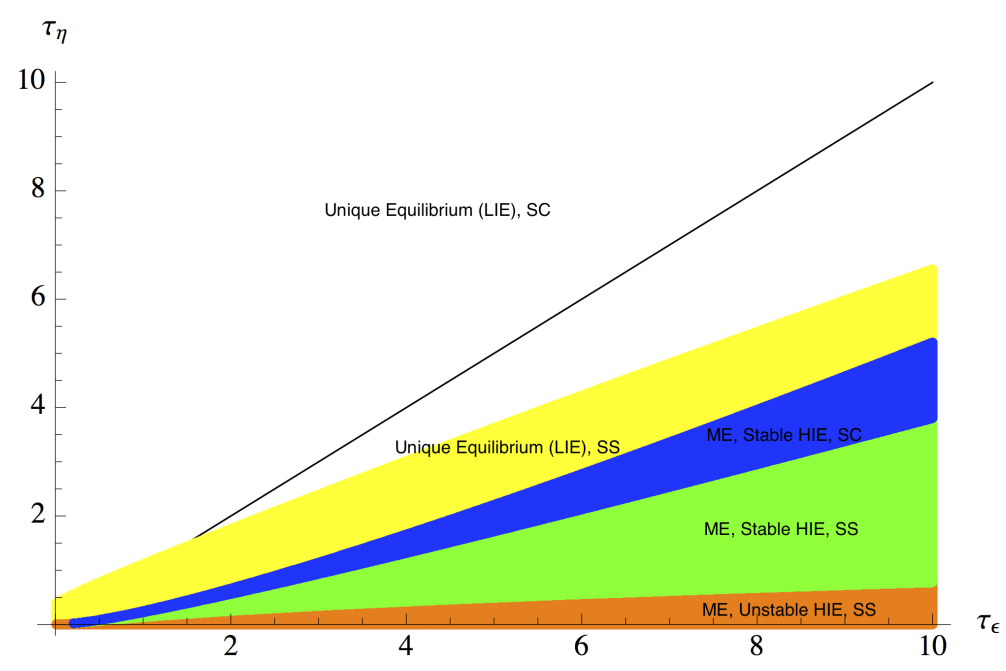

Figure 4: The equilibrium set, for $\beta=1, \gamma=1 / 2, \tau_{u}=\tau_{v}=10, \tau_{\eta} \in\{0, .01, \ldots, 10\}$, and $\tau_{\epsilon} \in\{.01, .02, \ldots, 10\}$. The black line denotes the set $\tau_{\eta}=\tau_{\epsilon}$. For values of $\left(\tau_{\epsilon}, \beta\right)$ in the white and yellow regions the equilibrium is unique, whereas when $\left(\tau_{\epsilon}, \beta\right)$ are in the other regions multiple equilibria (ME), in which depending on the value of $\tau_{\eta}$ vs. $\tau_{\epsilon}$ the HIE can be stable or unstable, obtain.

the market, and prices are semi-strong efficient. As a consequence, the retrospective inference loop breaks down, ensuring uniqueness ${ }^{26}$

It is also possible to show that the equilibrium is unique when investors have no private information $\left(\tau_{\epsilon}=0\right)$. In this case our model is akin to Grossman and Miller (1988), and investors only trade to accommodate liquidity traders' orders. Thus, prices are invertible in the latter's demand, and the retrospective inference loop once again breaks down, yielding uniqueness.

\subsubsection{Equilibrium strategies}

The next result characterizes investors' strategies:

Corollary 5. At a linear equilibrium, the strategies of an informed investor are given by

$$
\begin{gathered}
X_{1}\left(s_{i}, p_{1}\right)=\frac{a_{1}}{\alpha_{E_{1}}}\left(E_{i 1}[v]-p_{1}\right)+\frac{\alpha_{P_{1}}-\alpha_{E_{1}}}{\alpha_{E_{1}}} E_{1}\left[\theta_{1}\right] \\
X_{2}\left(s_{i}, s_{P}, p_{1}, p_{2}\right)=\frac{a_{2}}{\alpha_{E_{2}}}\left(E_{i 2}[v]-p_{2}\right) .
\end{gathered}
$$

\footnotetext{
${ }^{26}$ Note in particular that even with risk-neutral market makers, provided $\beta>0, a_{1}$ affects $z_{2}$, and $\lambda_{2}$. However, failing the need to estimate $\theta_{2}$, retrospective inference does not arise.
} 
When multiple equilibria arise and

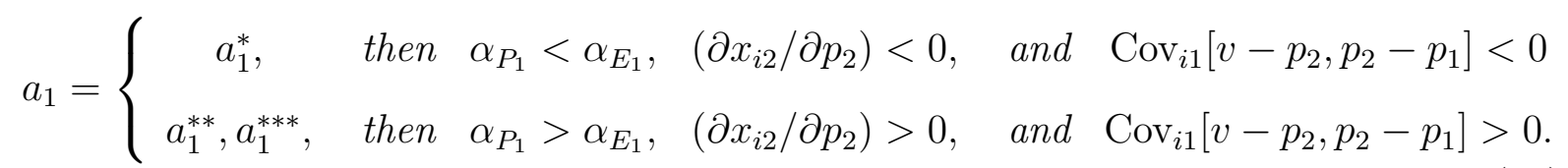

For $\beta=0, \alpha_{P_{1}}<\alpha_{E_{1}},\left(\partial x_{i 2} / \partial p_{2}\right)<0$, and $\operatorname{Cov}_{i 1}\left[v-p_{2}, p_{2}-p_{1}\right]<0$.

According to (20), in the second period an investor acts like in a static market. In the first period, instead, he loads his position anticipating the second period price, and scaling it down according to the uncertainty he faces on $p_{2}$, as shown by $(13)$. In this case, his strategy can be expressed as the sum of two components (see (19p)). The first component captures the investor's activity based on his private estimation of the difference between the fundamentals and the equilibrium price. This may be seen as akin to "long-term" speculative trading, aimed at taking advantage of the investor's superior information on the liquidation value of the asset, since $p_{2}$ is correlated with $v$. The second component captures the investor's activity based on the extraction of order flow, i.e. public, information. This trading is instead aimed at timing the market by exploiting short-run movements in the asset price determined by the evolution of the future aggregate demand. Along the HIE, the price is more driven by fundamentals. As a consequence, when observing

$$
E_{1}\left[\theta_{1}\right]=a_{1}\left(v-E_{1}[v]\right)+\theta_{1}>0
$$

the investor infers that this realization is more driven by fundamentals information and goes long in the asset, "chasing the trend." This is because he anticipates that second period investors will bid the price up when he unwinds his position, as implied by the sign of $\operatorname{Cov}_{i 1}\left[v-p_{2}, p_{2}-p_{1}\right]$. Along the LIE, prices are more driven by liquidity trading, and the trader acts instead as a "contrarian" investor 27

Remark 3. It is interesting to note that along the HIE, the asset is a Giffen good in the second period (see (21)). Differentiating $x_{i 2}$ with respect to $p_{2}$, we can break down the

\footnotetext{
${ }^{27}$ Note that traders in the model act as conditional momentum or contrarian investors. Indeed, a covariance decomposition shows that

$$
\operatorname{Cov}\left[v-p_{2}, p_{2}-p_{1}\right]=\operatorname{Cov}\left[E_{i 1}\left[v-p_{2}\right], E_{i 1}\left[p_{2}-p_{1}\right]\right]+\operatorname{Cov}_{i 1}\left[v-p_{2}, p_{2}-p_{1}\right]
$$
}


effect of a price increase into a substitution effect and an "information" effect:

$$
\frac{\partial X_{2}\left(s_{i}, s_{P}, p_{1}, p_{2}\right)}{\partial p_{2}}=\frac{a_{2}}{\alpha_{E_{2}}}(\underbrace{\frac{\partial E_{i 2}[v]}{\partial p_{2}}}_{\text {Information effect }}-\underbrace{1}_{\text {Substitution effect }}) .
$$

Along the HIE retrospective inference leads investors to rely a lot on prices and prices are very informative about the liquidation value. In this case the substitution effect is swamped by the information effect 28 Along the LIE, the opposite happens, and the asset is a normal good in the second period 29 Giffen goods tend to arise when learning from uninformed investors prevails and makes the aggregate information effect dominate the substitution effect (see e.g. Barlevy and Veronesi (2003), Yuan (2005), and Vives (2008)). This may also happen in the presence of feedback effects where prices are informative about both the fundamentals and the likelihood of coordination among informed investors as the feedback effect strengthens the information effect (as in Ozdenoren and Yuan $(2008))$.

Remark 4. The model can be extended to encompass the possibility that investors receive additional private signals at each trading round. The analysis becomes more complicated, without affecting the qualitative results. That is, in this case too we can show that multiple equilibria with the stated properties arise as long as $\beta>0$.

\subsubsection{Dynamic adjustment}

What is the effect of a shock to parameters' values on the equilibrium of the market? The answer to this question depends on whether the HIE is stable or not.

Starting from the case in which the HIE is stable, Figure 2 (panel (b)) implies that a decrease in private signal precision or in risk tolerance can have a non-monotone effect on $a_{1}$ and thus on the conditional volatility of returns, and informational efficiency of prices. To see this, consider first the case of private signal precision. Suppose that $\tau_{v}=\tau_{u}=10$, $\tau_{\epsilon}=9.5, \gamma=1 / 2, \tau_{\eta}=3$, and $\beta=1$. With these parameter values, the LIE and HIE are respectively $a_{1}^{*}=4.001$, and $a_{1}^{* * *}=5.606$, and correspond to the intersection of the orange best response function with the 45-degree line in Figure 5 (panel (a)). Suppose the market

\footnotetext{
${ }^{28}$ See Admati (1985) and Cespa (2005) for a discussion of the existence of Giffen assets due to information effects in the context of a multi-asset NREE model.

${ }^{29}$ To see this, note that $\partial x_{i 2} / \partial p_{2}=\left(a_{2} / \alpha_{E_{2}}\right)\left(\Delta a_{2} \tau_{u} / \lambda_{2} \tau_{i 2}-1\right)=-\gamma \tau_{i 2} /\left(1+\gamma \Delta a_{2} \tau_{u}\right)$. Along the HIE (LIE), as shown in Proposition $21+\gamma \Delta a_{2} \tau_{u}<0\left(1+\gamma \Delta a_{2} \tau_{u}>0\right)$, which proves the result.
} 
coordinates on the LIE. Suppose now that the precision of the private signal decreases to $\tau_{\epsilon}=7$. The new best response is depicted by the dashed curve in the figure. Again we have three equilibria with the LIE and HIE given respectively by $a_{1}^{*, N E W}=2.906$, and $a_{1}^{* * *, N E W}=4.124$ Which equilibrium does the market coordinate on? With adaptive dynamics, we can see that this will be the HIE. Thus, in this case a decrease in private signal precision determines an increase in the response to private information and informational efficiency, and a decrease in the conditional volatility of returns (along the initial LIE, $\operatorname{Var}_{1}\left[p_{2}\right]=0.00035$, while along the new HIE, $\left.\operatorname{Var}_{1}\left[p_{2}\right]=0.00013\right)$. Nonmonotonicity requires however a sufficiently large reduction in private precision ${ }^{31}$ Indeed, in panel (b) we repeat the same exercise, assuming that $\tau_{\epsilon}$ is lowered to 8 . In this case, adaptive dynamics implies that the new equilibrium along the dashed best response is the LIE. Panel (c) and (d) show that similar effects arise with a reduction in risk tolerance.

Consider now the case in which the HIE is unstable. In this situation numerical simulations show that starting from the HIE, the effect of a shock (even a very mild one) to parameters' values depends on the persistence of liquidity traders' demand. In detail: when $\beta \in(0,1)$, the equilibrium converges to the LIE; when $\beta=1$, the market oscillates between two non-equilibrium values, and the result is indeterminate. In Figure 6, panel (a) we plot the best response for $\tau_{v}=\tau_{u}=10, \tau_{\epsilon}=20, \gamma=1 / 2, \tau_{\eta}=1 / 2$, and $\beta=.9$. With these parameter values, the LIE and HIE are respectively $a_{1}^{*}=9.04$, and $a_{1}^{* * *}=12.25$, and the slope of the best response at these two points is given by $\psi^{\prime}\left(a_{1}^{*}\right)=-.41$ and $\psi^{\prime}\left(a_{1}^{* * *}\right)=-2.12$. As shown by the figure, starting from the HIE an iterated application of the best response leads the market to coordinate on the LIE. Consider now panel (b) where we plot the best response for $\tau_{v}=\tau_{u}=10, \tau_{\epsilon}=15$, $\gamma=1 / 2, \tau_{\eta}=1 / 2$, and $\beta=1$. With these parameter values, the LIE and HIE are respectively $a_{1}^{*}=6.64$, and $a_{1}^{* * *}=9.37$, and the slope of the best response at these two points is given by $\psi^{\prime}\left(a_{1}^{*}\right)=-.43$ and $\psi^{\prime}\left(a_{1}^{* * *}\right)=-1.9$. In this case, iterating the application of the best response starting from the HIE (after about 380 iterations) leads the market to oscillate between the non-equilibrium values 7.99 and 10.75 . Thus, the implication is that, provided $\beta<1$, if the market is at the HIE a small shock to parameter values leads it to the LIE.

\footnotetext{
${ }^{30}$ In both cases the HIE is stable case since $\left.\left(\partial \psi / \partial a_{1}\right)\right|_{a_{1}=a_{1}^{* * *}}=-.24$, and $\left.\left(\partial \psi / \partial a_{1}\right)\right|_{a_{1}=a_{1}^{* * * N E W}}=.35$.

${ }^{31}$ Denoting respectively by $\psi$ and $\psi^{N E W}$ the orange and dashed best responses, non monotonicity requires that that $\psi\left(a_{1}^{*}\right)>\psi^{N E W}\left(a_{1}^{* *, N E W}\right)$. If the reduction in private precision is such that $\psi\left(a_{1}^{*}\right)>$ $\psi^{N E W}\left(a_{1}^{* * *, N E W}\right)$, the new equilibrium along the dashed best response is still the HIE, but monotonicity
} 


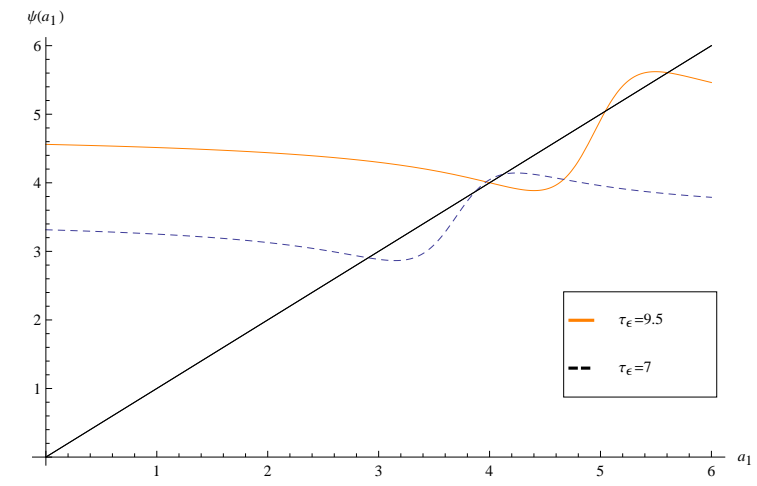

(a)

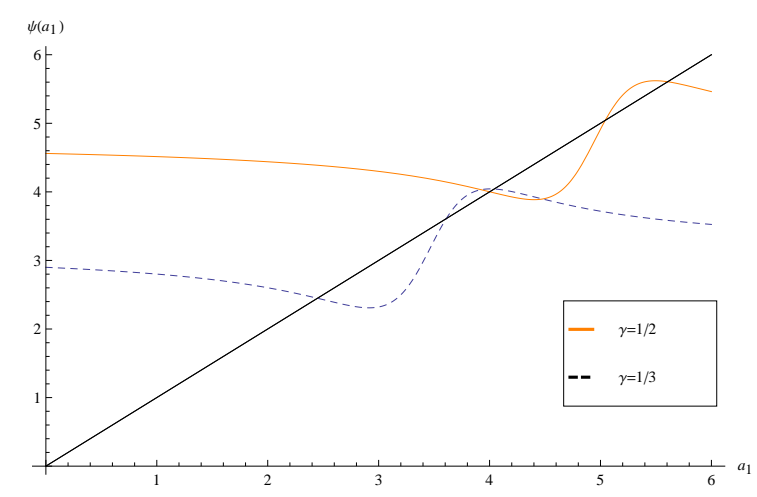

(c)

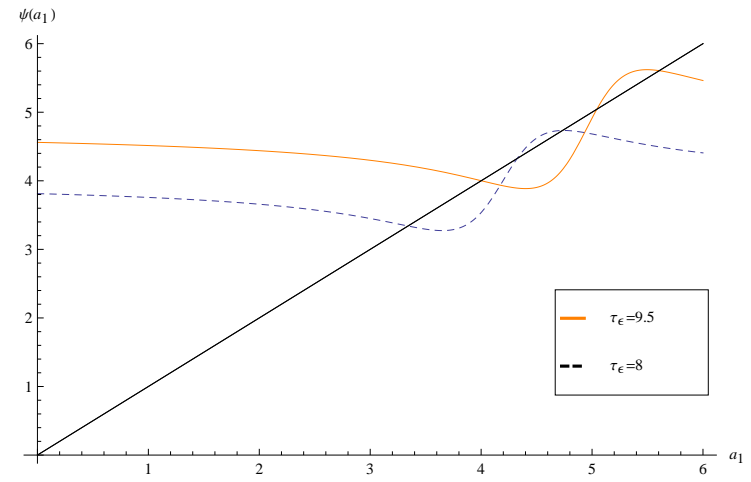

(b)

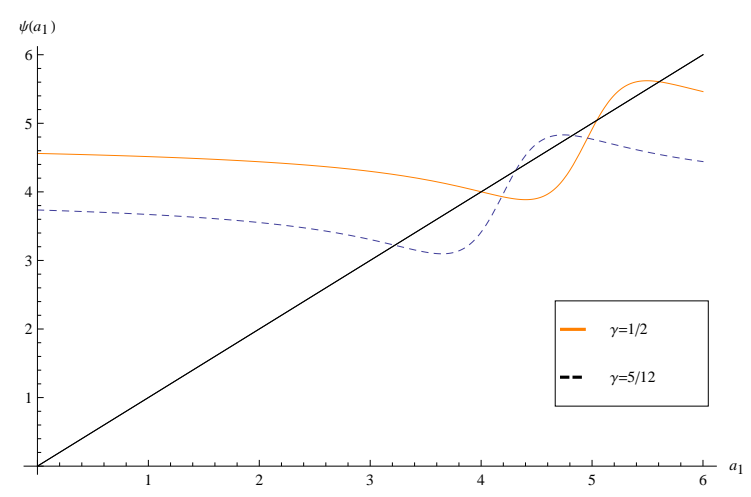

(d)

Figure 5: Adjustment to a shock when the HIE is stable. We plot the best response (16) for $\tau_{v}=\tau_{u}=10, \gamma=1 / 2, \tau_{\eta}=3, \beta=1$, and $\tau_{\epsilon}=9.5$ (orange). In panel (a) and (b) we analyze the effect of a reduction in the precision of the private signal to $\tau_{\epsilon}=7$ (dashed best response, panel (a)) and $\tau_{\epsilon}=8$ (dashed best response, panel (b)). In panel (c) and (d) we analyze the effect of a reduction in risk tolerance to $\gamma=1 / 3$ (dashed best response, panel (c)) and $\gamma=5 / 12$ (dashed best response, panel (d)).

\section{Average expectations and reliance on public infor- mation}

In this section we use our model to investigate the claim that when investors have a short horizon, prices reflect the latter HOEs about fundamentals and are farther away from the final payoff compared to average expectations (Allen, Morris, and Shin (2006)). We show here that with liquidity trading persistence investors use their private information also to infer the demand of liquidity traders from the first period price. Thus, the latter is driven is restored since $a_{1}^{* * *, N E W}<a_{1}^{*}$. 


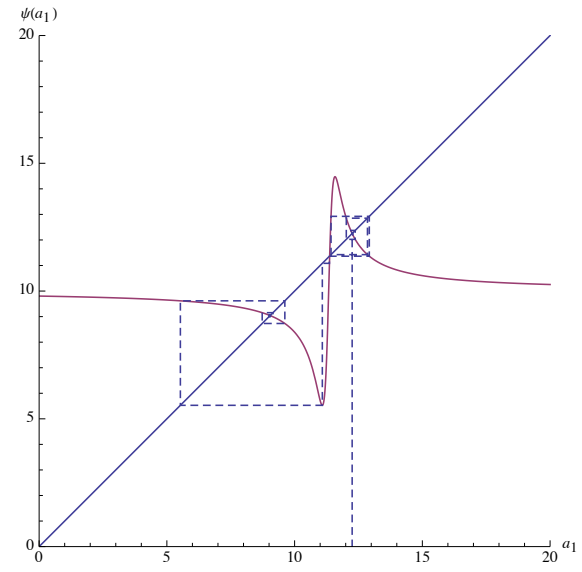

(a)

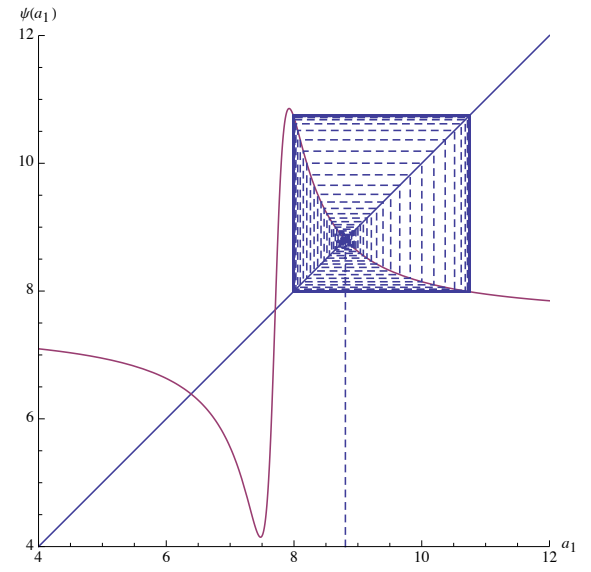

(b)

Figure 6: Adjustment to a shock when the HIE is unstable. In panel (a) we plot the best response (16) for $\tau_{v}=\tau_{u}=10, \tau_{\epsilon}=20, \gamma=1 / 2, \tau_{\eta}=1 / 2$, and $\beta=.9$. With these parameter values, the LIE and HIE are respectively $a_{1}^{*}=9.04$, and $a_{1}^{* * *}=12.25$, and the slope of the best response at these two points is given by $\psi^{\prime}\left(a_{1}^{*}\right)=-.41$ and $\psi^{\prime}\left(a_{1}^{* * *}\right)=-2.12$. In panel (b) we plot the best response 16 for $\tau_{v}=\tau_{u}=10, \tau_{\epsilon}=15$, $\gamma=1 / 2, \tau_{\eta}=1 / 2$, and $\beta=1$. With these parameter values, the LIE and HIE are respectively $a_{1}^{*}=6.64$, and $a_{1}^{* * *}=9.37$, and the slope of the best response at these two points is given by $\psi^{\prime}\left(a_{1}^{*}\right)=-.43$ and $\psi^{\prime}\left(a_{1}^{* * *}\right)=-1.9$.

by investors' HOEs about fundamentals and by their average expectations about liquidity trading. This, in turn, has implications for price reliance on public information. The consensus opinion about the fundamentals at time $n$ is denoted by $\bar{E}_{n}[v] \equiv \int_{0}^{1} E_{i n}[v] d i$. Note that $\bar{E}_{n}[v]=\alpha_{E_{n}} v+\left(1-\alpha_{E_{n}}\right) E_{n}[v]$.

Starting from the second period, and imposing market clearing yields

$$
\int_{0}^{1} X_{2}\left(s_{i}, s_{P}, p_{1}, p_{2}\right) d i+\theta_{2}=0
$$

Due to CARA and normality, we have

$$
X_{2}\left(s_{i}, s_{P}, p_{1}, p_{2}\right)=\gamma \frac{E_{i 2}[v]-p_{2}}{\operatorname{Var}_{i 2}[v]}
$$

Replacing the above in (23) and solving for the equilibrium price we obtain

$$
p_{2}=\bar{E}_{2}[v]+\Lambda_{2} \theta_{2}
$$


Similarly, in the first period, imposing market clearing yields:

$$
\int_{0}^{1} X_{1}\left(s_{i}, p_{1}\right) d i+\theta_{1}=0
$$

and solving for the equilibrium price we obtain

$$
p_{1}=\bar{E}_{1}\left[p_{2}\right]+\frac{\operatorname{Var}_{i 1}\left[p_{2}\right]}{\gamma} \theta_{1} .
$$

Substituting the above obtained expression for $p_{2}$ in 24 yields

$$
\begin{aligned}
p_{1} & =\bar{E}_{1}\left[\bar{E}_{2}[v]+\Lambda_{2} \theta_{2}\right]+\frac{\operatorname{Var}_{i 1}\left[p_{2}\right]}{\gamma} \theta_{1} \\
& =\bar{E}_{1}\left[\bar{E}_{2}[v]\right]+\beta \Lambda_{2} \bar{E}_{1}\left[\theta_{1}\right]+\frac{\operatorname{Var}_{i 1}\left[p_{2}\right]}{\gamma} \theta_{1} .
\end{aligned}
$$

According to (25), there are three terms that form the first period price: investors' second order average expectations over the liquidation value $\left(\bar{E}_{1}\left[\bar{E}_{2}[v]\right]\right)$, the risk-adjusted impact of the first period stock of liquidity trades $\left(\theta_{1}\right)$, and investors' average expectations over first period liquidity trades $\left(\bar{E}_{1}\left[\theta_{1}\right]\right)$. The latter arises since $p_{2}$ depends on $\theta_{2}$, which in turn is correlated with $\theta_{1}$ when $\beta>0$. Thus, investors in period 1 are also interested in estimating $\theta_{1}$.

Expression (25) implies that due to persistence in liquidity trading, the weight placed by the price on investors' average information is the sum of two terms: the first term captures the impact of HOEs on $v$, the second term reflects the impact of investors' average expectations over $\theta_{1}$. Computing

$$
\begin{aligned}
& \bar{E}_{1}\left[\bar{E}_{2}[v]\right]=\bar{\alpha}_{E_{1}} v+\left(1-\bar{\alpha}_{E_{1}}\right) E_{1}[v] \\
& \bar{E}_{1}\left[\theta_{1}\right]=a_{1}\left(1-\alpha_{E_{1}}\right)\left(v-E_{1}[v]\right)+\theta_{1}
\end{aligned}
$$

where

$$
\bar{\alpha}_{E_{1}}=\alpha_{E_{1}}\left(1-\frac{\tau_{1}}{\tau_{2}}\left(1-\alpha_{E_{2}}\right)\right) .
$$

Given (25), this implies that the total weight the price places on average private information is given by

$$
\alpha_{P_{1}}=\bar{\alpha}_{E_{1}}+\beta \Lambda_{2} a_{1}\left(1-\alpha_{E_{1}}\right)
$$

Note that for any $\beta, \bar{\alpha}_{E_{1}}<\alpha_{E_{1}}$. Thus, when liquidity trading is transient $(\beta=0)$ the 
first period price places a larger weight on public information than the optimal statistical weight. This finding is in line with Morris and Shin (2002), and Allen, Morris, and Shin $(2006)$. The latter prove that with heterogeneous information, prices reflect investors' HOEs about the final payoff. In this case, the law of iterated expectations does not hold, and investors' forecasts overweight public information. This happens because investors anticipate the average market opinion knowing that this also depends on the public information observed by other investors. The price is then systematically farther away from fundamentals compared to consensus.

However, when liquidity trading is persistent, $p_{1}$ also reflects investors' average expectations about the impact of first period liquidity traders on the second period price. Thus, an additional term adds to $\bar{\alpha}_{E_{1}}$ in the expression for $\alpha_{P_{1}}$ in (26). Along the HIE this increases the weight of the price on fundamentals above the optimal statistical weight as shown by the following result:

Corollary 6. Suppose $\tau_{\eta}>0$.

1. When $\beta \in(0,1]$, and multiple equilibria arise if

$$
a_{1}=\left\{\begin{array}{cccc}
a_{1}^{*}, & \text { then } \alpha_{P_{1}}<\alpha_{E_{1}}, & \text { and } & \operatorname{Cov}\left[p_{1}, v\right]<\operatorname{Cov}\left[\bar{E}_{1}[v], v\right] \\
a_{1}^{* * *}, & \text { then } \alpha_{P_{1}}>\alpha_{E_{1}}, & \text { and } & \operatorname{Cov}\left[p_{1}, v\right]>\operatorname{Cov}\left[\bar{E}_{1}[v], v\right]
\end{array}\right.
$$

2. When $\beta=0, \alpha_{P_{1}}<\alpha_{E_{1}}$ and $\operatorname{Cov}\left[p_{1}, v\right]<\operatorname{Cov}\left[\bar{E}_{1}[v], v\right]$.

With persistent liquidity trading, along the HIE, investors escalate their response to private information. In this case the extra weight that adds to $\bar{\alpha}_{E_{1}}$ is high enough to draw the price closer to fundamentals compared to consensus. In view of the results obtained in Section 4.1.1 this equilibrium is stable provided that private information is not too precise compared to the exogenous public signal. Along the equilibrium with low liquidity the price is farther away from fundamentals compared to consensus. This equilibrium, which shares the same properties of the one found by Allen, Morris, and Shin (2006), is instead always stable.

Remark 5. According to Numerical Result 1 and Corollary 3 , the inventory component of liquidity is larger in the LIE than in the HIE. This offers an alternative interpretation for Corollary 6. when prices are farther away from (closer to) fundamentals compared to consensus, inventory risk is high (low). Empirically, this suggests that the inventory component of liquidity should be increasing in the extent to which asset prices are farther away from fundamentals compared to consensus. 
Remark 6. The model can be generalized in different ways: (i) adding more trading dates, (ii) allowing second period investors to receive a new signal about the fundamentals and (iii) assuming that the fundamentals has an additive factor structure $v+\delta$, with $\delta \sim N\left(0, \tau_{\delta}^{-1}\right)$ independent of all the other random variables in the model, and such that no investor is informed about it ${ }^{32}$ All these extensions complicate the analysis, without modifying its qualitative implications. More in detail, extending the trading horizon to more than 2 periods has the effect of widening the set of equilibria, and generating a richer dynamic. For example, when $\tau_{\eta}=0$ and $\beta>0$, numerical simulations show that typically $2^{(N-1)}$ equilibria obtain. In these equilibria along some paths prices alternate between dates in which $\alpha_{P_{n}}>\alpha_{E_{n}}$ and dates in which $\alpha_{P_{n}}<\alpha_{E_{n}}$. However, in our numerical simulations it is always possible to find an equilibrium path in which $\alpha_{P_{n}}>\alpha_{E_{n}}$ $\left(\alpha_{P_{n}}<\alpha_{E_{n}}\right)$ for all $n=1,2, \ldots, N$. Allowing second period investors to receive a fresh signal still delivers the HIE and LIE with the stated properties. Finally, assuming a factor structure for the asset payoff makes the equilibrium dependent on the solution of a system of a cubic and a 13-degree equation. Our simulations show that, depending on parameters' values, 5, 3 or 1 equilibrium arise. When multiple equilibria obtain, at most two of them are stable, and the one with the highest responsiveness to private information inherits the properties of the HIE.

\section{$6 \quad$ Asset pricing implications}

In this section we investigate the asset pricing implications of our analysis. In particular, we show that liquidity trading persistence can generate positive autocovariance of returns, without the need to impose heterogenous beliefs (as in Banerjee, Kaniel, and Kremer (2009)) or to assume that investors' preferences display a behavioral bias (as in, e.g., Daniel, Hirshleifer, and Subrahmanyam (1998)). We then look at the expected volume of informational trading and, consistently with the evidence presented in Llorente, Michaely, Saar, and Wang (2002), we find that in our setup a high volume of informational trading predicts momentum. Finally, we derive a set of empirical implications that allow to distinguish the HIE from the LIE.

\footnotetext{
${ }^{32}$ This corresponds to the model with "residual uncertainty" analyzed by He and Wang (1995) and Cespa and Vives (2012) among others.
} 


\subsection{Return autocovariance}

We start by computing the return autocovariance at different horizons:

Corollary 7. Suppose $\tau_{\eta}>0$. At equilibrium:

1. For all $\beta \in[0,1], \operatorname{Cov}\left[p_{2}-p_{1}, p_{1}-\bar{v}\right]<0$.

2. For $\beta \in(0,1], \operatorname{Cov}\left[v-p_{2}, p_{1}-\bar{v}\right]<0$. For $\beta=0, \operatorname{Cov}\left[v-p_{2}, p_{1}-\bar{v}\right]=0$.

3. For $\beta \in(0,1]$, when multiple equilibria arise, along the HIE

$$
\operatorname{Cov}\left[v-p_{2}, p_{2}-p_{1}\right]>0
$$

If $\beta=0, \operatorname{Cov}\left[v-p_{2}, p_{2}-p_{1}\right]<0$.

According to the above result, along the HIE, momentum occurs at short horizons (close to the end of the trading horizon), whereas at a longer horizon, returns display reversal 33 This is in line with the empirical findings on return anomalies that document the existence of positive return autocorrelation at short horizons (ranging from six to twelve months, see Jegadeesh and Titman (1993)), and negative autocorrelation at long horizons (from three to five years, see De Bondt and Thaler (1985)).

The first two results derive from the fact that a given estimated first period imbalance, $E_{1}\left[\theta_{1}\right]$, has an opposite effect on $p_{1}-\bar{v}$, and $p_{2}-p_{1}, v-p_{2}{ }^{34}$ For the third result, a covariance decomposition (and the normality of returns) yields:

$$
\begin{aligned}
\operatorname{Cov}\left[v-p_{2}, p_{2}-\right. & \left.p_{1}\right]= \\
= & \operatorname{Cov}\left[E_{1}\left[v-p_{2}\right], E_{1}\left[p_{2}-p_{1}\right]\right]+\operatorname{Cov}_{1}\left[v-p_{2}, p_{2}-p_{1}\right] \\
= & \beta \Lambda_{2} \frac{\operatorname{Var}_{i 1}\left[p_{2}\right]}{\gamma} \operatorname{Var}\left[E_{1}\left[\theta_{1}\right]\right]+\frac{\left(1+\gamma \tau_{u} \Delta a_{2}\right)\left(\beta a_{1} \Delta a_{2} \tau_{u}-\tau_{1}\right)+\gamma \tau_{\eta} \tau_{u} \beta a_{1}}{\left(\gamma \tau_{i 2}\right)^{2} \tau_{1} \tau_{u}} .
\end{aligned}
$$

The first term in the above decomposition captures the covariation of the conditional returns' forecasts $E_{1}\left[v-p_{2}\right]$ and $E_{1}\left[p_{2}-p_{1}\right]$, that is the covariance "explained" by $p_{1}$. The second term captures the conditional covariariation of returns, that is, the "residual" covariance. All else equal, with persistence the anticipated impact of the first period imbalance has the same sign on both the second and third period expected returns, so

\footnotetext{
${ }^{33}$ Numerical simulations show that in a model with three periods, along the HIE, both $\operatorname{Cov}\left[v-p_{3}, p_{3}-\right.$ $\left.p_{2}\right]$ and $\operatorname{Cov}\left[p_{3}-p_{2}, p_{2}-p_{1}\right]$ are positive.

${ }^{34} \mathrm{As}$ one can verify $\operatorname{Cov}\left[v-p_{2}, p_{1}-\bar{v}\right]=\operatorname{Cov}\left[E_{1}\left[v-p_{2}\right], E_{1}\left[p_{1}-\bar{v}\right]\right]=-\beta \Lambda_{2} \operatorname{Cov}\left[E_{1}\left[\theta_{1}\right], p_{1}\right]<0$, and $\operatorname{Cov}\left[p_{2}-p_{1}, p_{1}-\bar{v}\right]=\operatorname{Cov}\left[E_{1}\left[p_{2}-p_{1}\right], E_{1}\left[p_{1}-\bar{v}\right]\right]=\left(\beta \Lambda_{2}-\Lambda_{1}\right) \operatorname{Cov}\left[E_{1}\left[\theta_{1}\right], p_{1}\right]<0$.
} 
that the first term is always positive when $\beta>0$. Intuitively, suppose that in the first period investors estimate a selling pressure from liquidity traders. If $p_{1}<p_{2}$ the outcome $p_{2}<v$ is more likely than $p_{2} \geq v$, because liquidity traders' sales of the asset are likely to persist in the second period 35

For the second term, factoring out the impact of first period information, the joint covariation of returns around their expectations could be driven either by liquidity trading or by fundamentals information. In the HIE, as prices are driven by informed traders, the second effect predominates and returns positively covary around their means ${ }^{36}$ Conversely, in the LIE, prices are more driven by liquidity trades, so that returns tend to covary around their means in opposite directions.

When $\tau_{\eta}=0$ all of the results obtained in Corollary 7 hold. Furthermore, we can prove that provided $\beta$ is sufficiently high, momentum occurs at short horizons also along the LIE (numerical simulations confirm this result also for the case $\tau_{\eta}>0$ ):

Corollary 8. Suppose $\tau_{\eta}=0$. Along the LIE, for $\tau_{v}<\hat{\tau}_{v}$, there exists a value $\hat{\beta}$ such that for all $\beta>\hat{\beta}, \operatorname{Cov}\left[v-p_{2}, p_{2}-p_{1}\right]>0$ (the expression for $\hat{\tau}_{v}$ is given in the appendix, see equation (A.30).

Along the LIE momentum is a sign of strong liquidity trading persistence and is due to the effect of the covariance explained by $p_{1}$ in (27). This is consistent with the fact that in this equilibrium prices are driven by liquidity trades, so that the predictability of returns is in this case a sign of poor informational efficiency. Indeed, it is possible to show that when $\beta$ is sufficiently large, momentum also arises in a model with no private information 37 Along the HIE, however, momentum occurs for any value of $\beta$. This means that even though (a very mild) persistence is required, momentum in this case does not reflect the impact of liquidity trading. On the contrary, due to the properties of the HIE illustrated in Proposition 2, it is rather a sign of rapid price convergence to the fundamentals. In the next section we provide a numerical illustration of the different properties of prices along the two equilibria.

Remark 7. Equation (27) shows that optimal investment behavior in our model departs in a substantial way from the one of an outside observer that relies on the sign of the

\footnotetext{
${ }^{35}$ Thus, liquidity trades persistence offsets the mean reversion effect due to first period short-term investors' unwinding at date 2.

${ }^{36}$ Recall that in this case, Proposition 2 shows that $1+\gamma \tau_{u} \Delta a_{2}<0$, which due to 27 immediately implies that $\operatorname{Cov}_{1}\left[v-p_{2}, p_{2}-p_{1}\right]>0$.

${ }^{37}$ This can be seen by computing $\lim _{\tau_{\epsilon} \rightarrow 0} \operatorname{Cov}\left[v-p_{2}, p_{2}-p_{1}\right]=\left(\beta-\gamma^{2} \tau_{v} \tau_{u}\right) / \gamma^{4} \tau_{u}^{2} \tau_{v}^{3}$, which implies that momentum in this case arises when $\beta>\gamma^{2} \tau_{v} \tau_{u}$.
} 
unconditional return covariance to trade. Indeed, an investor in our model engages in momentum trading only for a stock that displays a very strong positive autocovariance. Equivalently, he may adopt a contrarian strategy even when an outside observer would see $\operatorname{Cov}\left[v-p_{2}, p_{2}-p_{1}\right]>0$. This is because, as argued in Corollary 5 , informed investors base their decision to chase the trend or act as contrarians on the sign of $\operatorname{Cov}_{i 1}\left[v-p_{2}, p_{2}-p_{1}\right]$, since they can perfectly anticipate $E_{1}\left[\theta_{1}\right]$.

\subsection{Expected volume and return predictability}

We now turn our attention to the implications of our results for the expected volume of informational trading.

We start by computing the expected traded volume in the market with heterogeneous information net of the expected volume that obtains in the market with no private information. This yields: 38

$$
\begin{aligned}
V_{1} & \equiv \int_{0}^{1} E\left[\left|X_{1}\left(s_{i}, p_{1}\right)\right|\right] d i-\int_{0}^{1} E\left[\left|X_{1}\left(p_{1}\right)\right|\right] d i \\
& =\int_{0}^{1} \sqrt{\frac{2}{\pi} \operatorname{Var}\left[X_{1}\left(s_{i}, p_{1}\right)\right]} d i-\int_{0}^{1} \sqrt{\frac{2}{\pi} \operatorname{Var}\left[X_{1}\left(p_{1}\right)\right]} d i \\
& =\sqrt{\frac{2}{\pi}}\left(\sqrt{a_{1}^{2} \tau_{\epsilon}^{-1}+\tau_{u}^{-1}}-\sqrt{\tau_{u}^{-1}}\right)
\end{aligned}
$$

and

$$
\begin{aligned}
V_{2} & \equiv \int_{0}^{1} E\left[\left|X_{2}\left(s_{i}, p_{1}, p_{2}\right)-X_{1}\left(s_{i}, p_{1}\right)\right|\right] d i-\int_{0}^{1} E\left[\left|X_{2}\left(p_{1}, p_{2}\right)-X_{1}\left(p_{1}\right)\right|\right] d i \\
& \left.=\int_{0}^{1} \sqrt{\frac{2}{\pi} \operatorname{Var}\left[X_{2}\left(s_{i}, p_{1}, p_{2}\right)-X_{1}\left(s_{i}, p_{1}\right)\right.}\right] d i-\int_{0}^{1} \sqrt{\frac{2}{\pi} \operatorname{Var}\left[X_{2}\left(p_{1}, p_{2}\right)-X_{1}\left(p_{1}\right)\right]} d i \\
& =\sqrt{\frac{2}{\pi}}\left(\sqrt{\left(a_{1}-a_{2}\right)^{2} \tau_{\epsilon}^{-1}+\left(1+(\beta-1)^{2}\right) \tau_{u}^{-1}}-\sqrt{\left(1+(\beta-1)^{2}\right) \tau_{u}^{-1}}\right)
\end{aligned}
$$

We measure the total volume of informational trading with $V_{1}+V_{2}$, and obtain the following result:

Corollary 9 (Expected volume of informational trading). Suppose $\tau_{\eta}>0$. At equilibrium, for all $\beta \in(0,1]$ the expected volume of informational trading is higher along

\footnotetext{
${ }^{38}$ In a market with no private information, investors only absorb liquidity traders' orders. Therefore, at equilibrium their position only reflects liquidity traders' demand, and $E\left[\left|x_{1}\right|\right]=\left((2 / \pi) \tau_{u}^{-1}\right)^{1 / 2}$. This is the approach used in, e.g., He and Wang (1995).
} 
the HIE. When $\beta=0$ only the equilibrium with a low volume of informational trading survives.

Proof. Rearranging the expressions for investors' strategies obtained in Corollary 5 yields $x_{i n}=a_{n} \epsilon_{i n}-\theta_{n}$, for $n=1,2$. For a normally distributed random variable $Y$ we have

$$
E[|Y|]=\sqrt{\frac{2}{\pi} \operatorname{Var}[Y]} .
$$

Therefore, as $a_{1}^{* * *}>a_{1}^{*}$, according to (28) $V_{1}$ is larger along the HIE. According to 29), $V_{1}+V_{2}$ is an increasing function of $a_{1}$ for $a_{1}>a_{2}$, a condition that is satisfied along the HIE. Finally, from Corollary 2 when $\beta=0, a_{1}^{*}<a_{2}$.

The intuition for the above result is straightforward: as along the HIE investors step up the response to their signals, the position change due to private information is higher along such equilibrium. Taken together, Corollaries 7 and 9 imply that a high volume of informational trading in the second period predicts return continuation, no matter what the persistence in liquidity trading is, in line with the evidence presented by Llorente, Michaely, Saar, and Wang (2002). A low volume of informational trading, on the other hand, can also be associated with momentum, provided liquidity trading is sufficiently persistent. In this case, though, momentum is a signal of slow price convergence to the liquidation value. In sum, momentum is compatible with both a high and a low volume of informational trading, but the implications that return continuation has for price informativeness are markedly different in the two situations.

Large trading volume is often related to the presence of disagreement among investors' forecasts of the asset payoff (see e.g, Kandel and Pearson (1995)). In our setup, we can measure disagreement as follows:

$$
\operatorname{Disag}=\operatorname{Var}\left[E_{\text {in }}[v]-\bar{E}_{n}[v]\right]=\operatorname{Var}\left[\alpha_{E_{n}} \epsilon_{i}\right]=\frac{\tau_{\epsilon}}{\tau_{\text {in }}^{2}}
$$

From the above expression and Proposition 2 we therefore conclude that disagreement is low (high) along the HIE (LIE). Given Corollary 9, this implies that volume is large in the equilibrium with low disagreement. The reason for this result is as follows. From expressions (28) and (29) we see that volume is increasing in $a_{1}^{2} / \tau_{\epsilon}$. Using (13) we have

$$
\frac{a_{1}^{2}}{\tau_{\epsilon}}=\left(\gamma \frac{\lambda_{2} \Delta a_{2}}{\operatorname{Var}_{i 1}\left[p_{2}\right]}\right)^{2} \operatorname{Var}\left[\alpha_{E_{1}} \epsilon_{i}\right] .
$$


The first component on the right hand side of the above expression captures the effect of investors' perceived risk on volume, whereas the second term coincides with our definition for disagreement. Along the HIE (LIE) we know that disagreement is low (high) but we also know that investors face little (a lot of) risk over the price at which they unwind their position. The latter effect prevails in our setup, implying that a large volume is a proxy for low disagreement and low perceived risk. This prediction is in line with some authors who document that large volume around earnings announcements is compatible with convergence of opinions (see, e.g., Giannini, Irvine, and Shu (2013)).

Finally, our findings on volume are also related to Banerjee (2011) and Kondor (2012). The former compares Difference of Opinions (DO) models to Rational Expectations (RE) ones. One prediction is that in a DO model, differently from a RE one, the conditional volatility of returns is negatively related to expected volume. Coupling Corollary 9 with Numerical Result 1, this is precisely what happens in our RE setup with strategic complementarities, even though investors agree on a common prior. Kondor (2012) studies a 2-period trading model with a three-factor fundamentals and short-term trading. Investors have differential information on a subset of factors and, in the presence of a noisy public signal about the fundamentals (that is the sum of the three factors), HOEs over the average of the factor they do not know, which is instead imperfectly observed by the agents that absorb their positions. In this model, the public signal generates disagreement, because it induces traders to compare their factor-specific private information to the public signal, to gauge the magnitude of the missing factor. Kondor (2012) shows that an increase in public signal informativeness, by augmenting disagreement, can generate large volume, and more informative and volatile prices (conditional on the public signal). Our model can also produce similar patterns. However, in our setup the burst in trades accompanied by higher price volatility is due to the fact that a sufficiently precise public signal can stabilize the HIE 39

\subsection{Empirical implications}

Expression (27) and Corollary 8 clarify that momentum in our model is due to liquidity trading persistence. The behavioral finance literature has focused on different mechanisms

\footnotetext{
${ }^{39}$ For example, setting $\tau_{u}=\tau_{v}=10, \tau_{\epsilon}=1, \tau_{\eta}=.2, \gamma=1 / 2$, and $\beta=1$, we obtain two stable equilibria $a_{1}^{*}=.29$ and $a_{1}^{* * *}=.86$. Because of Corollary 9 , volume is higher along the HIE. Furthermore, calculating price volatility yields $\operatorname{Var}\left[p_{1}\right]^{* * *}=.05$ and $\operatorname{Var}\left[p_{2} \mid s_{P}\right]^{* * *}=.07$, while $\operatorname{Var}\left[p_{1}\right]^{*}=.02$, and $\operatorname{Var}\left[p_{2} \mid s_{P}\right]^{*}=.04$. Thus, price volatility is 1.7 (2.6) larger in the HIE compared to the LIE in the first (second) period.
} 
to explain the nature of returns' predictability, each one requiring some form of departure from rational behavior and implying a breakdown of market efficiency 40 Our analysis shows instead that due to persistence, momentum can arise in a model in which all agents are rational and in which, depending on the equilibrium that arises, a given demand shock from liquidity traders yields stock prices that are either very informationally efficient (along the HIE) or very poor signals of underlying fundamentals (along the LIE, provided $\beta$ is high enough).

To illustrate this point, in Figure 7 we plot the simulated price paths along the LIE, the HIE and the unique equilibrium that obtains assuming that traders have no private information (that is, $\tau_{\epsilon}=0$ ), and positions of liquidity traders at dates 1 and 2 . The plots are obtained extracting 1,000 iid normal shocks for $v, u_{1}, u_{2}$, and $\eta$, and averaging across the prices and shocks 41

The parameters' values are as follows: $\bar{v}=40, \tau_{v}=0.01, \tau_{u}=0.1, \tau_{\epsilon}=1, \gamma=$ $1 / 2, \tau_{\eta}=0.001862$, and $\beta=1 / 2$. With these values the HIE is stable $\left(\left\{a_{1}^{*}, a_{1}^{* * *}\right\}=\right.$ $\{0.012,41.25\}$, and $\left.\left\{\psi^{\prime}\left(a_{1}^{*}\right), \psi^{\prime}\left(a_{1}^{* * *}\right)\right\}=\{-0.012,-0.92\}\right)$ and we get momentum along the LIE and in the equilibrium with no private information, as shown in Table 1 .

\begin{tabular}{lccc}
\hline & LIE & HIE & Equilibrium with $\tau_{\epsilon}=0$ \\
\hline $\operatorname{Cov}\left[v-p_{2}, p_{2}-p_{1}\right]$ & 735.019 & 0.000007 & $4.79052 \times 10^{8}$ \\
$\operatorname{Cov}_{1}\left[v-p_{2}, p_{2}-p_{1}\right]$ & -37.0281 & 0.000007 & $-284,279$ \\
$\operatorname{Cov}\left[z_{1}, p_{2}-p_{1}\right]$ & -801.224 & $-1.67227 \times 10^{-6}$ & $-5.68589 \times 10^{6}$ \\
$E_{1}\left[v-p_{1}\right]$ & -81.0874 & -0.00472533 & $-568,673$ \\
$E_{1}\left[p_{2}-p_{1}\right]$ & -80.1224 & $-1.67227 \times 10^{-7}$ & $-568,589$ \\
\hline
\end{tabular}

Table 1: Autocovariance of returns (unconditional and conditional), return predictability from order flows, and expected returns from liquidity provision in the numerical example.

Panel (a) displays the position of liquidity traders, which in this simulation is on aver${ }^{40}$ Hong and Stein Hong and Stein $(2007)$ argue that predictability involves a departure from standard
models with rational agents. Such departure entails either the adoption of models with standard prefer-
ences, but biased beliefs as in Daniel, Hirshleifer, and Subrahmanyam $(1998)$; alternatively, models with
non-conventional preferences and rational beliefs as in Barberis and Huang $(2001)$; finally, predictability
can arise in models with heterogeneous agents as in Hong and Stein $(1999)$.
${ }^{41}$ The green line in panels $(\mathrm{b}),(\mathrm{c})$ and $(\mathrm{d})$ is the $\log$ of the average of the semi strong efficient prices
obtained in the simulations, that is $\ln \left((1 / 1,000) \sum_{j=1}^{1,000} E_{n j}[v]\right), n=1,2$. The horizontal line in the plots
for the price paths is the log of the average value of the fundamentals $\ln (38.08) \approx 3.64$ in this simulation. 


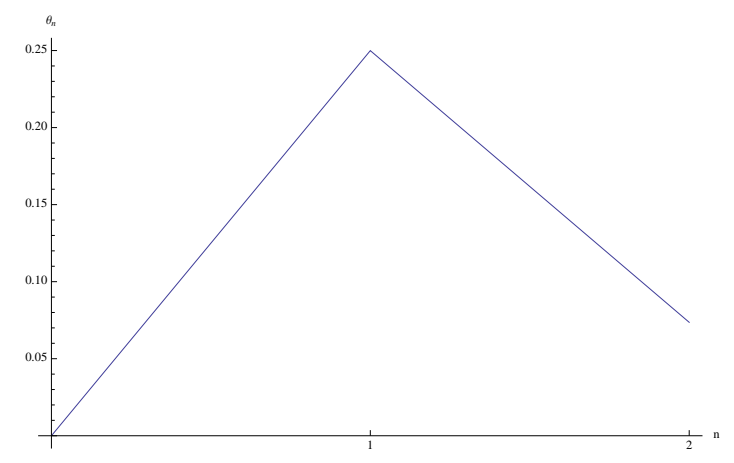

(a)

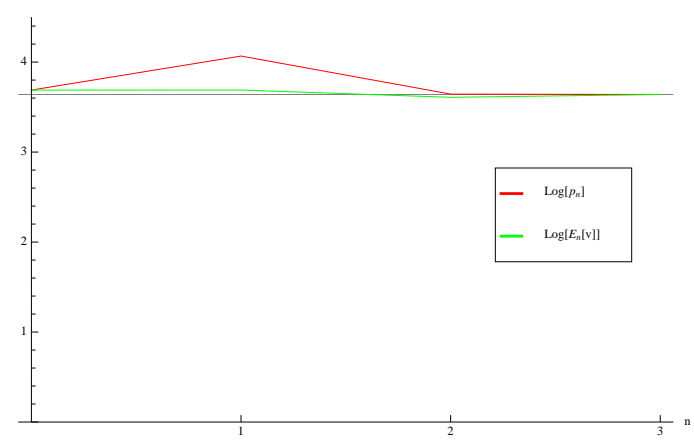

(c)

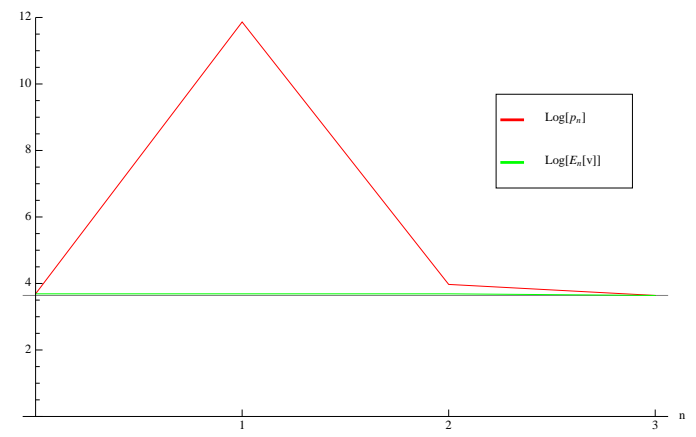

(b)

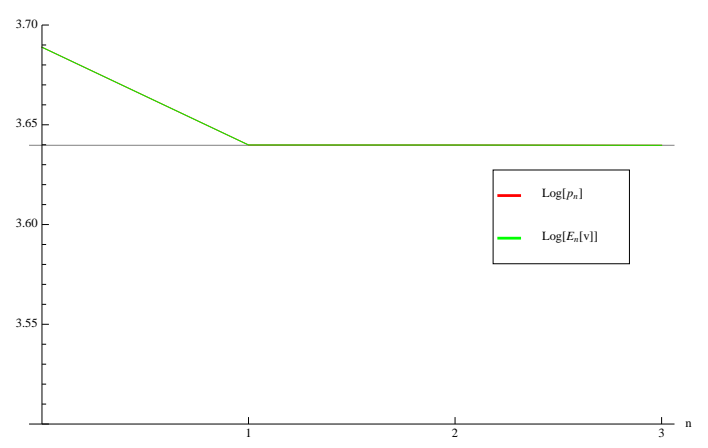

(d)

Figure 7: Liquidity traders' demand (panel (a)) and the path of prices (red) and semi strong efficient prices (green) along the equilibrium with no private information, the LIE, and the HIE (respectively, panel (b), (c), and (d)). Parameters' values are as follows: $\bar{v}=40, \tau_{v}=.01, \tau_{u}=.1, \tau_{\epsilon}=1, \gamma=1 / 2, \tau_{\eta}=.001862$, and $\beta=1 / 2$.

age positive at both dates. According to panel (b), in the absence of private information, prices mirror liquidity traders' demand. Indeed, as short term traders are risk averse, they require a compensation to meet the positive demand of liquidity traders that is proportional to their perceived uncertainty about the payoff. This drives $p_{1}$ above $\bar{v}$ in this equilibrium. Moving to panel (c) shows that prices display a qualitatively similar behavior along the LIE. However, as traders are informed, $a_{n}>0$ and part of liquidity traders' shock is accommodated by offsetting, speculative (in this numerical example sell) orders. As such orders transmit information, they diminish investors' perceived uncertainty about the payoff, which implies that the price adjustment needed to accommodate $\theta_{n}$ is lower compared to the case $\tau_{\epsilon}=0$. Thus, without private information and in the LIE, the price path reflects liquidity traders' position and is therefore hump-shaped. Along the HIE (panel (d)), on the contrary, the first period price almost exactly coincides with the semi-strong efficient price, and with the full information value. In this equilibrium, 
traders aggressively speculate (sell) against the liquidity (buy) shock $\theta_{n}$ based on their private information. This drives $p_{1}$ below $\bar{v}$ and close to $v$, making price adjustment much more rapid. As these trades are highly informative, they dramaticaly diminish investors' perceived uncertainty about the payoff, which explains why the price almost coincides with $E_{n}[v]$, even though the risk-bearing capacity of the market is limited $(\gamma<\infty)$. In this equilibrium short term trading offsets the impact of liquidity traders' orders on prices, and the price path is inversely hump-shaped.

These different patterns suggest that (i) the compensation investors receive to supply liquidity should be larger in the LIE than in the HIE, and (ii) that the short term predictability of prices based on order flow information $\left(z_{1}\right)$ should be higher along the LIE compared to the HIE. Both predictions are confirmed by the last three rows of Table $14^{42}$ The latter prediction is also consistent with the evidence presented by Chordia, Roll, and Subrahmanyam (2008) who find that short-horizon return predictability from order flows diminishes when the market is more liquid.

Combining these observations with Proposition 2 and Corollary 3 suggests a way to identify the HIE and the LIE from the data. Our model predicts that for extreme values of public signal precision, the LIE arises. This equilibrium is characterized by (i) a positive inference component of the price impact, (ii) momentum or reversal depending on the strength of persistence, (iii) high expected returns from liquidity provision and prices that are far apart from the semi-strong efficient price, and (iv) strong short-horizon return predictability from order imbalances. Conversely, for intermediate values of public signal precision, the HIE can also arise. This equilibrium obtains with (i) a negative inference component of the price impact, (ii) mild momentum, (iii) low expected returns from liquidity provision and prices that are close to the semi-strong efficient price, and (iv) weak short-horizon return predictability from order imbalances.

These findings offer several empirical predictions. At a daily or intra-daily level, one could test our model's implications by looking at the informational content of the prices of comparable stocks that differ in terms of the sign of their respective inference components of the spread. The prices of stocks with a negative inference component should be more informationally efficient, or closer to their semi-strong efficient prices.

At a lower frequeny, our findings have implications for the literature that tests the effect of strategic complementarities in asset markets. For example, Chen, Goldstein, and

\begin{tabular}{|l|}
\hline \hline${ }^{42}$ The expected returns from liquidity provision are calculated per unit of expected demand from liq- \\
\hline uidity traders, $E_{1}\left[\theta_{1}\right]=1$. Note that since $E_{1}\left[v-p_{2}\right]=-\beta \Lambda_{2} E_{1}\left[\theta_{1}\right], E_{1}\left[p_{2}-p_{1}\right]=\left(\beta \Lambda_{2}-\Lambda_{1}\right) E_{1}\left[\theta_{1}\right]$, \\
expected returns are only due to the inventory component of liquidity, consistently with our interpreta- \\
\hline tion.
\end{tabular}


Jiang (2010) show that the sensitivity of outflows to bad past performace is stronger in mutual funds that invest mostly in illiquid securities, than in those that invest in more liquid securities. This is because if following bad performance some investors redeem their shares in an illiquid fund, the latter is forced to liquidate at a steep discount. Such a devaluation only affects the investors who do not redeem, which spurs a "run for the exit," that magnifies price pressure. As shown in the above simulation, in our setup the impact of a given price pressure $\theta_{n}$ (due, e.g., to the cumulative decision to redeem) depends on which equilibrium arises. Thus, we should expect that the sensitivity of outflows to bad past performance should be stronger (weaker) in funds for which a large part of the securities feature a positive (negative) inference component of the spread.

The predictions of our model are also consistent with a narrative of the recent financial crisis that emphasizes the role of private and public information. Several authors have pointed out that investors' selling pressure determined a reduction of asset values below fundamentals (followed by a rebound. See, e.g. Cella, Ellul, and Giannetti (2013)). One reason why such large corrections occurred is possibly lack of (or "slow moving") arbitrage capital (Duffie (2010)), which exhausted the risk bearing capacity of liquidity suppliers. Our theory provides an alternative explanation which stresses the fact that the informational conditions that could have allowed a milder correction were not in place. Especially, a paucity of reliable public information (proxied by a reduction in $\tau_{\eta}$ ), may have reduced the risk bearing capacity of the market, relegating most of the economy to the LIE ${ }^{43}$ As argued in Section 4.1 .3 if the market coordinates at a HIE which, due to poor public information is unstable, a further mild shock to public information leads it to the LIE. Indirect evidence of such a transition can be found in the fact that "contrarian," liquidity-providing strategies proved to be especially profitable during the financial crisis (as documented by Nagel (2012)), in line with the prediction of the LIE derived in this section. In this respect our paper makes the additional prediction that in the cross section, one should observe that the assets that were hit by the most extreme corrections were those with poorer public information 44

Finally, our model can also explain the effects of stress tests' results disclosure in the US. Interestingly, Peristian, Morgan, and Savino (2010) in their analysis of the Supervisory Capital Assessment Plan (SCAP), argue that while stress tests did not communicate anything new to investors about which banks were in trouble, they allowed a better gauge

\footnotetext{
${ }^{43}$ For instance, Gorton and Metrick (2010) argue that in the recent crisis repo depositors "did not know which securitized banks were most likely to fail."

${ }^{44}$ Nagel (2012) finds that during the crisis, the stocks of small, illiquid, and high-volatility companies offered the largest contrarian returns.
} 
of troubled banks' capital shortfall. Furthermore, they also find that following SCAP announcement, the stock prices of the banks with capital gaps became more volatile than those of the banks with no gap. Within our model, this in line with a situation in which private information (investors' private assessment of troubled banks' capital gap) is not overly less informative than public signals (the actual capital gaps), which allows the HIE to be stable. In this situation, the provision of public information allows the market to coordinate on the low-volatility HIE for non-gap banks, and on the LIE for gap banks.

Remark 8. We know from Jovanovic (1989) that identification problems in models with multiple equilibria of the structural parameters governing the model are severe and that "the set of distributions on observable outcomes that are consistent with a given structure can be quite large." Positive identification results are obtained in a range of papers that use simple models with multiple equilibria (such as discrete entry or binary games; see the account in Ackerberg, Lanier Benkard, Berry, and Pakes (2007) and Berry and Tamer $(2006))$. Identification of structural parameters is achieved through equilibrium refinements, shape restrictions, informational assumptions or the specification of equilibrium selection mechanisms. Alternatively, inference can be based on the identified features of the models with multiple equilibria (which are sets of values of the structural parameter vector, see e.g. Ciliberto and Tamer (2009) and the refinement in Henry and Galichon (2011)).

In our case when we have two stable equilibria there is no equilibrium refinement or equilibrium selection mechanism to be used. A promising approach, given the presence of strategic complementarities in our model, is the one of Echenique and Komunjer (2009) based on monotone comparative statics (MCS) results. However, unfortunately, the type of multiplicity that arises in our paper fails to satisfy MCS, which this literature needs for identification. For example, Figure 3 shows that the MCS property fails to hold with respect to the precision of the public signal. Indeed, an increase in $\tau_{\eta}$ from 0 to 5 , decreases (increases) $a_{1}$ along the the HIE and IIE (LIE) ${ }^{45}$

\section{Conclusions}

In this paper we argue that the persistence in liquidity traders' positions has an important effect on risk-averse, short-term investors' response to their private signals. When

\footnotetext{
${ }^{45} \mathrm{~A}$ similar non-monotone pattern arises also with respect to other parameters of the model. Thus, this methodology cannot be applied in our model. We however feel that given the set of empirical implications we have derived, identification should be less of a problem.
} 
liquidity traders' orders are correlated across trading dates, investors reassess the evidence about the fundamentals obtained at the early trading stage, based on the new information gathered in the market. Such "retrospective" inference can generate strategic complementarities in the use of private information which can yield multiple, stable equilibria that can be ranked in terms of price informativeness, liquidity, and volatility.

Our analysis shows that in the presence of uninformed orders' predictability, the impact of investors' short horizons on the market depends on the quality of public information. When public information is not overly precise compared to private signals, the retrospective inference channel is not too strong, and a stable equilibrium with low volatility, and high liquidity and price informativeness arises. This equilibrium exists along another equilibrium where prices are more volatile, less informationally efficient, and the market is thinner. Thus, our analysis can guide the empirical literature investigating the effect of investors' horizons on market patterns to identify stock characteristics that are associated with the high or low volatility equilibrium. For example, we show that in the low volatility equilibrium the inference component of liquidity is negative.

Our analysis also clarifies the role of HOEs in asset pricing. With liquidity trading persistence, prices are driven by average expectations about fundamentals and liquidity trading. This, in contrast to the beauty contest results of Allen, Morris, and Shin (2006), can draw prices either systematically farther away from or closer to fundamentals compared to investors' consensus (respectively, along the LIE and the HIE). We show that when public information is either overly precise compared to private signals or very poor, prices are farther away from fundamentals compared to consensus. However, a public signal of intermediate precision makes the HIE stable, thereby drawing prices closer to the fundamentals compared to consensus. We also link the HIE and LIE to the magnitude of the inventory component of liquidity, and to the returns from liquidity supply. Thus, our analysis establishes the limits of the beauty contest analogy for financial markets and provides empirical implications to assess the effect of HOEs on asset prices.

Finally, our paper provides an alternative interpretation for empirically documented regularities on the patterns of return autocorrelation. As we have argued, at long horizons returns display reversal. However, return correlation at short horizons depends on the equilibrium that prevails in the market. In the HIE, investors escalate their response to private information and momentum arises. Conversely, in the LIE investors scale down their response to private signals and, when liquidity trading is not very persistent, returns tend to revert. While this offers an explanation for returns' predictability which departs from behavioral assumptions, our analysis also makes the empirical prediction 
that both a high or a low volume of informational trading can predict momentum. In the former case, this is a signal that prices rely poorly on public information and accurately reflect fundamentals starting from the earlier stages of the trading process. In this case momentum at short horizons proxies for a rapid price convergence to the full information value. In the latter case, instead, prices heavily rely on public information and offer a poor signal of fundamentals. In this case, therefore, momentum proxies for a continuing, liquidity-driven, price pressure. The empirical literature has only recently started to investigate the relationship between empirical regularities like the momentum effect, and the role of HOEs in asset prices (see e.g., Verardo (2009)). Our paper offers clear empirical predictions in this respect, uncovering the existence of two types of momentum with very different informational properties. This can guide further research in the empirical analysis of asset pricing anomalies. 


\section{References}

Ackerberg, D., C. Lanier Benkard, S. Berry, and A. Pakes (2007, January). Econometric tools for analyzing market outcomes. In J. Heckman and E. Leamer (Eds.), Handbook of Econometrics, Volume 6 of Handbook of Econometrics, Chapter 63. Elsevier.

Admati, A. R. (1985). A noisy rational expectations equilibrium for multi-asset securities markets. Econometrica 53(3), 629-657.

Admati, A. R. and P. Pfleiderer (1988). A theory of intraday patterns: volume and price variability. Review of Financial Studies 1(1), 3-40.

Albagli, E. (2011). Amplification of uncertainty in illiquid markets. Working Paper.

Allen, F., S. Morris, and H. S. Shin (2006). Beauty contests and iterated expectations in asset markets. Review of Financial Studies 19(3), 719-752.

Avdis, E. (2012). Information trade-offs in dynamic financial markets. Working Paper.

Bacchetta, P. and E. van Wincoop (2006). Can information heterogeneity explain the exchange rate determination puzzle? American Economic Review 96(3), 552-576.

Bacchetta, P. and E. van Wincoop (2008). Higher order expectations in asset pricing. Journal of Money, Credit and Banking 40(5), 837-866.

Banerjee, S. (2011). Learning from prices and the dispersion in beliefs. Review of Financial Studies 24(9), 3025-3068.

Banerjee, S., R. Kaniel, and I. Kremer (2009). Price drift as an outcome of differences in higher order beliefs. Review of Financial Studies 22(9), 3707-3734.

Barberis, N. and M. Huang (2001). Mental accounting, loss aversion and individual stock returns. Journal of Finance 56, 1247-1292.

Barlevy, G. and P. Veronesi (2003). Rational panics and stock market crashes. Journal of Economic Theory 110(2), 234-263.

Berry, S. and E. Tamer (2006). Identification in Models of Oligopoly Entry, Volume Advances in Economics and Econometrics. Cambridge University Press.

Biais, B., P. Bossaerts, and C. Spatt (2010). Equilibrium asset pricing and portfolio choice under asymmetric information. Review of Financial Studies 23(4), 15031543. 
Bond, P., I. Goldstein, and E. S. Prescott (2010, February). Market-based corrective actions. Review of Financial Studies 23(2), 781-820.

Brown, D. P. and R. H. Jennings (1989). On technical analysis. Review of Financial Studies 2(4), 527-551.

Campbell, J. Y. and A. S. Kyle (1993, January). Smart money, noise trading and stock price behaviour. Review of Economic Studies 60(1), 1-34.

Cella, C., A. Ellul, and M. Giannetti (2013). Investors' horizons and the amplification of market shocks. Review of Financial Studies 26(7), 1607-1648.

Cespa, G. (2002). Short-term investment and equilibrium multiplicity. European Economic Review 46(9), 1645-1670.

Cespa, G. (2005). Giffen goods and market making. Economic Theory 25(4), 983-997.

Cespa, G. and X. Vives (2012). Dynamic trading and asset prices: Keynes vs. Hayek. Review of Economic Studies 79, 539-580.

Cespa, G. and X. Vives (2013). The welfare impact of high frequency trading. Working Paper.

Chen, Q., I. Goldstein, and W. Jiang (2010). Payoff complementarities and financial fragility: Evidence from mutual fund outflows. Journ of Financial Economics 97, 239-262.

Chen, Q., Z. Huang, and Y. Zhang (2012). The effects of public information with asymmetrically informed short-horizon investors. Working Paper (http://ssrn.com/abstract=1944328).

Chevalier, J. and G. Ellison (1997). Risk taking by mutual funds as a response to incentives. Journal of Political Economy 105, 1167-1200.

Chordia, T., R. Roll, and A. Subrahmanyam (2008, February). Liquidity and market efficiency. Journal of Financial Economics 87(2), 249-268.

Chordia, T. and A. Subrahmanyam (2004). Order imbalance and individual stock returns: Theory and evidence. Journal of Financial Economics 72(3), 485-518.

Ciliberto, F. and E. Tamer (2009). Market structure and multiple equilibria in airline markets. Econometrica $77(6), 1791-1828$.

Coval, J. and E. Stafford (2007). Asset fire sales (and purchases) in equity markets. Journal of Financial Economics 86(2), 479-512. 
Daniel, K., D. Hirshleifer, and A. Subrahmanyam (1998). Investor psychology and security market under- and overreactions. Journal of Finance 53, 1839-1884.

De Bondt, W. F. M. and R. Thaler (1985). Does the stock market overreact? Journal of Finance 40(3), 793-805.

De Long, J. B., A. Shleifer, L. H. Summers, and R. J. Waldmann (1990). Noise trader risk in financial markets. Journal of Political Economy 98(4), 703-738.

Dennert, J. (1991). Insider trading and the cost of capital in a multi-period economy. London School of Economics Financial Market Group Discussion Paper 128.

Dow, J. (2005). Self-sustaining liquidity in an asset market with asymmetric information. Journal of Business 7r(895-908).

Dow, J., I. Goldstein, and A. Guembel (2011). Incentives for information production in markets where prices affect real investment. Working Paper.

Dow, J. and G. Gorton (1994). Arbitrage chains. Journal of Finance 49(3), 819-49.

Duffie, D. (2010). Presidential address: Asset price dynamics with slow-moving capital. Journal of Finance 65(4), 1237-1267.

Echenique, F. and I. Komunjer (2009, 07). Testing models with multiple equilibria by quantile methods. Econometrica $77(4), 1281-1297$.

Foucault, T., M. Pagano, and A. Roöell (2013). Market Liquidity. Oxford University Press.

Froot, K. A., D. S. Scharfstein, and J. C. Stein (1992). Herd on the street: Informational inefficiencies in a market with short-term speculation. Journal of Finance 47(4), 1461-1484.

Ganguli, J. V. and L. Yang (2009). Complementarities, multiplicity, and supply information. Journal of the European Economic Association 7(1), 90-115.

Giannini, R., P. Irvine, and T. Shu (2013). The convergence and divergence of investors' opinions around earnings news: Evidence from a social network. Working Paper.

Goldstein, I., E. Ozdenoren, and K. Yuan (2013). Trading frenzies and their impact on real investment. Journal of Financial Economics 109(2), 566 - 582.

Goldstein, I. and L. Yang (2012). Information diversity and market efficiency spirals. Working Paper. 
Gorton, G. and A. Metrick (2010). Haircuts. Federal Reserve Bank of St. Louis Review (92), 507-517.

Griffin, J. M., J. H. Harris, and S. Topaloglu (2003). The dynamics of institutional and individual trading. The Journal of Finance 58(6), 2285-2320.

Gromb, D. and D. Vayanos (2010). Limits of arbitrage: The state of the theory. Annual Review of Financial Economics 2, 251-275.

Grossman, S. J. and M. H. Miller (1988). Liquidity and market structure. Journal of Finance 43(3), 617-37.

Grossman, S. J. and J. E. Stiglitz (1980). On the impossibility of informationally efficient markets. American Economic Review 70(3), 393-408.

Haldane, A. G. and R. Davies (2011). The short long. Bank of England working paper.

Hamm, S. J. W. (2010). The effect of ETFs on stock liquidity. Working Paper, Wharton.

He, H. and J. Wang (1995). Differential information and dynamic behavior of stock trading volume. Review of Financial Studies 8(4), 919-972.

Henker, T. and J.-X. Wang (2006, May). On the importance of timing specifications in market microstructure research. Journal of Financial Markets 9(2), 162-179.

Henry, M. and A. Galichon (2011). Set identification in models with multiple equilibria. Review of Economic Studies 78(4), 1264-1298.

Holmström, B. and J. Ricart i Costa (1986). Managerial incentives and capital management. Quarterly Journal of Economics 101, 835-860.

Hong, H. and J. C. Stein (1999). A unified theory of underreaction, momentum trading, and overreaction in asset markets. Journal of Finance 54 (6), 2143-2184.

Hong, H. and J. C. Stein (2007). Disagreement and the stock market. Journal of Economic Perspectives 21(2), 109-128.

Huang, R. and H. Stoll (1997). The components of the bid-ask spread: a general approach. Review of Financial Studies 10(4), 995-1034.

Jegadeesh, N. and S. Titman (1993). Returns to buying winners and selling losers: Implications for stock market efficiency. Journal of Finance 48, 65-91.

Jovanovic, B. (1989, November). Observable implications of models with multiple equilibria. Econometrica 57(6), 1431-1437. 
Kandel, E. and N. D. Pearson (1995). Differential interpretation of public signals and trade in speculative markets. Journal of Political Economy 103(4), 831-872.

Kondor, P. (2012). The more we know, the less we agree on the price. Review of Economic Studies 79(3), 1175-1209.

Kyle, A. (1985). Continuous auctions and insider trading. Econometrica 53(6), 13151336.

Llorente, G., R. Michaely, G. Saar, and J. Wang (2002). Dynamic volume-return relation of individual stocks. Review of Financial Studies 15(4), 1005-1047.

Lou, D. (2012). A flow-based explanation for return predictability. Review of Financial Studies 25(12), 3457-3489.

Madhavan, A., M. Richardson, and M. Roomans (1997). Why do security prices change? a transaction-level analysis of nyse stocks. The Review of Financial Studies 10(4), 1035-1064.

Morris, S. and H. S. Shin (2002). The social value of public information. American Economic Review 92, 1521-1534.

Nagel, S. (2012). Evaporating liquidity. Review of Financial Studies 25(7), 2005-2039.

Nimark, K. P. (2007). Dynamic higher order expectations. Working Paper.

Ozdenoren, E. and K. Yuan (2008). Feedback effects and asset prices. Journal of Finance 63(4), 1939-1975.

Pagano, M. (1989). Endogenous market thinness and stock-price volatility. Review of Economic Studies 56, 269-288.

Peristian, S., D. P. Morgan, and V. Savino (2010). The information value of the stress test and bank opacity. Federal Reserve Bank of New York, Staff Reports.

Shleifer, A. and R. Vishny (1990). Equilibrium short horizons of investors and firms. American Economic Review 80, 148-153.

Singleton, K. J. (1987). Asset prices in a time-series model with disparately informed, competitive traders. In W. Barnett and K. Singleton (Eds.), New approaches to monetary economics. Cambridge University Press, Cambridge.

Sirri, E. R. and P. Tufano (1998). Costly search and mutual fund flows. Journal of Finance 53, 1589-1622. 
Spiegel, M. (1998). Stock price volatility in a multiple security overlapping generations model. Review of Financial Studies 11(2), 419-447.

Van Ness, B., R. A. Van Ness, and R. S. Warr (2001). How well do adverse selection components measure adverse selection? Financial Management 30(3), 5-30.

Vayanos, D. and P. Woolley (2013). An institutional theory of momentum and reversal. Review of Financial Studies (forthcoming).

Verardo, M. (2009). Heterogeneous beliefs and momentum profits. Journal of Financial and Quantitative Analysis 44(04), 795-822.

Vives, X. (1995). Short-term investment and the informational efficiency of the market. Review of Financial Studies 8(1), 125-160.

Vives, X. (2008). Information and Learning in Markets: The Impact of Market Microstructure. Princeton University Press.

Watanabe, M. (2008). Price volatility and investor behavior in an overlapping generations model with information asymmetry. Journal of Finance 63(1), 229-272.

Yuan, K. (2005). Asymmetric price movements and borrowing constraints: A rational expectations equilibrium model of crises, contagion, and confusion. Journal of Finance 60(1), 379-411.

Zhang, J. (2012). Learning, short-horizons, and asset pricing. Yale Working Paper. 


\section{A Appendix}

\section{Proof of Proposition 1}

Consider a candidate linear (symmetric) equilibrium and let $z_{1} \equiv a_{1} v+\theta_{1}$ be the noisy informational addition about $v$ generated by informed investors in period 1 (the "informational content" of the first period order flow) and simlarly $z_{2} \equiv \Delta a_{2} v+u_{2}$ where $\Delta a_{2} \equiv a_{2}-\beta a_{1}$ for the second period. We now show that $p_{1}$ is observationally equivalent (o.e.) to $z_{1}$ and that, given $s_{P}$, the sequence $\left\{z_{1}, z_{2}\right\}$ is o.e. to $\left\{p_{1}, p_{2}\right\}$. Consider a candidate linear (symmetric) equilibrium $x_{i 1}=a_{1} s_{i}-\varphi_{1}\left(p_{1}\right), x_{i 2}=a_{2} s_{i}+b s_{P}-\varphi_{2}\left(p_{1}, p_{2}\right)$, where $\varphi_{n}(\cdot)$ is a linear function. Letting $x_{n} \equiv \int_{0}^{1} x_{i n} d i$, and imposing market clearing in the first period implies (due to our convention):

$$
x_{1}+\theta_{1}=0 \Longleftrightarrow a_{1} v+\theta_{1}=\varphi_{1}\left(p_{1}\right) \text {. }
$$

In the second period the market clearing condition is

$$
\begin{aligned}
x_{2}+\beta \theta_{1}+u_{2}=0 & \Longleftrightarrow x_{2}-\beta x_{1}+u_{2}=0 \\
& \Longleftrightarrow a_{2} v+b s_{P}-\varphi_{2}\left(p_{1}, p_{2}\right)-\beta\left(a_{1} v-\varphi_{1}\left(p_{1}\right)\right)+u_{2}=0 \\
& \Longleftrightarrow \Delta a_{2} v+u_{2}=\varphi_{2}\left(p_{1}, p_{2}\right)-\beta \varphi_{1}\left(p_{1}\right)-b s_{P},
\end{aligned}
$$

where in the second line we use (A.1). From A.1 and A.2 it is easy to see that $z_{1}$ is o.e. to $p_{1}$ and that $\left\{z_{1}, z_{2}\right\}$ is o.e. to $\left\{p_{1}, p_{2}\right\}$. It thus follows that $E_{1}[v]=\tau_{1}^{-1}\left(\tau_{v} \bar{v}+a_{1} \tau_{u} z_{1}\right)$, $E_{2}[v]=\tau_{2}^{-1}\left(\tau_{1} E_{1}[v]+\tau_{\eta} s_{P}+\Delta a_{2} \tau_{u} z_{2}\right), \operatorname{Var}_{1}[v] \equiv \tau_{1}^{-1}=\left(\tau_{v}+a_{1}^{2} \tau_{u}\right)^{-1}, \operatorname{Var}_{2}[v] \equiv \tau_{2}^{-1}=$ $\left(\tau_{1}+\tau_{\eta}+\Delta a_{2}^{2} \tau_{u}\right)^{-1}, E_{\text {in }}[v]=\tau_{\text {in }}^{-1}\left(\tau_{n} E_{n}[v]+\tau_{\epsilon} s_{i}\right)$, and $\operatorname{Var}_{i n}[v] \equiv \tau_{\text {in }}^{-1}=\left(\tau_{n}+\tau_{\epsilon}\right)^{-1}$.

To prove our argument, we proceed by backwards induction. In the last trading period traders act as in a static model and owing to CARA and normality we have

$$
X_{2}\left(s_{i}, s_{P}, z_{1}, z_{2}\right)=\gamma \frac{E_{i 2}[v]-p_{2}}{\operatorname{Var}_{i 2}[v]}
$$

and denoting by $\bar{E}_{2}[v] \equiv \int_{0}^{1} E_{i 2}[v] d i$,

$$
\begin{aligned}
p_{2} & =\bar{E}_{2}[v]+\frac{\operatorname{Var}_{i 2}[v]}{\gamma} \theta_{2} \\
& =\alpha_{P_{2}}\left(v+\frac{\theta_{2}}{a_{2}}\right)+\left(1-\alpha_{P_{2}}\right) E_{2}[v]
\end{aligned}
$$


where

$$
\begin{gathered}
a_{2}=\gamma \tau_{\epsilon} \\
\alpha_{P_{2}}=\alpha_{E_{2}} .
\end{gathered}
$$

Rearranging A.4 we obtain

$$
\begin{aligned}
p_{2} & =\frac{\alpha_{P_{2}}}{a_{2}}\left(a_{2} v-\beta a_{1} v+\beta a_{1} v+\theta_{2}\right)+\left(1-\alpha_{P_{2}}\right) E_{2}[v] \\
& =(\underbrace{\frac{\alpha_{P_{2}}}{a_{2}}+\left(1-\alpha_{P_{2}}\right) \frac{\Delta a_{2} \tau_{u}}{\tau_{2}}}_{\lambda_{2}}) z_{2}+\frac{\tau_{\eta}}{\tau_{i 2}} s_{P}+\frac{\gamma \tau_{1} E_{1}[v]+\beta z_{1}}{\gamma \tau_{i 2}} \\
& =\lambda_{2} z_{2}+\frac{\tau_{\eta}}{\tau_{i 2}} s_{P}+\frac{\beta \alpha_{P_{2}}}{a_{2}} z_{1}+\left(1-\alpha_{P_{2}}\right) \frac{\tau_{1}}{\tau_{2}} E_{1}[v],
\end{aligned}
$$

which provides an alternative expression for $p_{2}$ which separates the impact on second period "news" from the information contained in the first period price and the public signal.

In the first period owing to CARA and normality, an agent $i$ trades according to

$$
X_{1}\left(s_{i}, z_{1}\right)=\gamma \frac{E_{i 1}\left[p_{2}\right]-p_{1}}{\operatorname{Var}_{i 1}\left[p_{2}\right]}
$$

where, using A.6,

$$
\begin{gathered}
E_{i 1}\left[p_{2}\right]=\left(\lambda_{2} \Delta a_{2}+\frac{\tau_{\eta}}{\tau_{i 2}}\right) E_{i 1}[v]+\frac{\gamma \tau_{1} E_{1}[v]+\beta z_{1}}{\gamma \tau_{i 2}} \\
\operatorname{Var}_{i 1}\left[p_{2}\right]=\left(\lambda_{2} \Delta a_{2}+\frac{\tau_{\eta}}{\tau_{i 2}}\right)^{2} \frac{1}{\tau_{i 1}}+\frac{\lambda_{2}^{2}}{\tau_{u}}+\frac{\tau_{\eta}}{\tau_{i 2}^{2}}
\end{gathered}
$$

Replacing A.8 and A.9 in A.7 yields

$$
\begin{aligned}
X_{1}\left(s_{i}, z_{1}\right) & =\gamma \frac{\left(\lambda_{2} \Delta a_{2}+\tau_{\eta} / \tau_{i 2}\right) E_{i 1}[v]}{\operatorname{Var}_{i 1}\left[p_{2}\right]}+\frac{\gamma}{\operatorname{Var}_{i 1}\left[p_{2}\right]}\left(\frac{\beta \alpha_{P_{2}}}{a_{2}} z_{1}+\left(1-\alpha_{P_{2}}\right) \frac{\tau_{1}}{\tau_{2}} E_{1}[v]\right)-\frac{\gamma}{\operatorname{Var}_{i 1}\left[p_{2}\right]} p_{1} \\
& =a_{1} s_{i}+\frac{a_{1} \tau_{1}}{\tau_{\epsilon}} E_{1}[v]+\frac{\gamma}{\operatorname{Var}_{i 1}\left[p_{2}\right]}\left(\frac{\beta \alpha_{P_{2}}}{a_{2}} z_{1}+\left(1-\alpha_{P_{2}}\right) \frac{\tau_{1}}{\tau_{2}} E_{1}[v]\right)-\frac{\gamma}{\operatorname{Var}_{i 1}\left[p_{2}\right]} p_{1},
\end{aligned}
$$

where

$$
a_{1}=\gamma \frac{\left(\lambda_{2} \Delta a_{2}+\tau_{\eta} / \tau_{i 2}\right) \alpha_{E_{1}}}{\left(\lambda_{2} \Delta a_{2}+\tau_{\eta} / \tau_{i 2}\right)^{2} / \tau_{i 1}+\lambda_{2}^{2} / \tau_{u}+\tau_{\eta} / \tau_{i 2}^{2}} .
$$


Imposing market clearing: $x_{1}+\theta_{1}=0$, which implies

$$
a_{1} v+\theta_{1}+\frac{a_{1} \tau_{1}}{\tau_{\epsilon}} E_{1}[v]+\frac{\gamma}{\operatorname{Var}_{i 1}\left[p_{2}\right]}\left(\frac{\beta \alpha_{P_{2}}}{a_{2}} z_{1}+\left(1-\alpha_{P_{2}}\right) \frac{\tau_{1}}{\tau_{2}} E_{1}[v]\right)=\frac{\gamma}{\operatorname{Var}_{i 1}\left[p_{2}\right]} p_{1}
$$

Finally, solving for the equilibrium price and collecting terms yields

$$
p_{1}=\underbrace{a_{1}\left(\frac{\operatorname{Var}_{i 1}\left[p_{2}\right]}{\gamma}+\frac{\beta \alpha_{P_{2}}}{a_{2}}\right)}_{\alpha_{P_{1}}}\left(v+\frac{\theta_{1}}{a_{1}}\right)+\left(1-\alpha_{P_{1}}\right) E_{1}[v] .
$$

\section{Proof of Corollary 1}

In the second period, rearranging A.4 , $p_{2}=E_{2}[v]+\Lambda_{2} E_{2}\left[\theta_{2}\right]$, where $\Lambda_{2}=\operatorname{Var}_{i 2}[v] / \gamma$. In the first period, from A.11 we have

$$
\alpha_{P_{1}}=a_{1}\left(\frac{\operatorname{Var}_{i 1}\left[p_{2}\right]}{\gamma}+\beta \frac{\operatorname{Var}_{i 2}[v]}{\gamma}\right) .
$$

By definition of the inventory component obtained in (7), $\Lambda_{1}=\alpha_{P_{1}} / a_{1}$. This implies

$$
\Lambda_{1}=\frac{\operatorname{Var}_{i 1}\left[p_{2}\right]}{\gamma}+\beta \frac{\operatorname{Var}_{i 2}[v]}{\gamma}
$$

\section{$\underline{\text { Proof of Corollary } 2}$}

For the second period price, see A.6). For the first period price, we rearrange (A.11) to obtain

$$
p_{1}=(\underbrace{\frac{\alpha_{P_{1}}}{a_{1}}+\left(1-\alpha_{P_{1}}\right) \frac{a_{1} \tau_{u}}{\tau_{1}}}_{\lambda_{1}}) z_{1}+\left(1-\alpha_{P_{1}}\right) \frac{\tau_{v}}{\tau_{1}} \bar{v} .
$$




\section{Proof of Proposition 2}

To prove existence it suffices to note that in the first period, the equilibrium responsiveness to private information is defined by the fixed points of the following function

$$
\psi\left(a_{1}\right)=\gamma \frac{\left(\lambda_{2} \Delta a_{2}+\tau_{\eta} / \tau_{i 2}\right) \alpha_{E_{1}}}{\left(\lambda_{2} \Delta a_{2}+\tau_{\eta} / \tau_{i 2}\right)^{2} / \tau_{i 1}+\lambda_{2}^{2} / \tau_{u}+\tau_{\eta} / \tau_{i 2}^{2}} .
$$

By inspection $\phi\left(a_{1}\right) \equiv a_{1}-\psi\left(a_{1}\right)=0$ is a quintic in $a_{1}$, and therefore always possesses a real root. Note that at equilibrium $a_{1}>0$, otherwise $\lambda_{2} \Delta a_{2}>0$, which in view of A.13 yields a contradiction.

Suppose that $\beta>0$. To prove multiplicity we proceed as follows. Note that

$$
\begin{gathered}
\phi(0)=-\gamma^{2} \tau_{\epsilon} \tau_{u}\left(a_{2}+\gamma\left(\tau_{\eta}+a_{2}^{2} \tau_{u}\right)\right)\left(\tau_{\epsilon}+\tau_{\eta}+a_{2}^{2} \tau_{u}+\tau_{v}\right)<0 \\
\phi\left(a_{2}\right)>0 .
\end{gathered}
$$

Therefore, there exists an equilibrium $a_{1}^{*} \in\left(0, a_{2}\right)$. Next, evaluating $\phi(\cdot)$ at

$$
a_{1}=\frac{1+\gamma \tau_{u} a_{2}}{\gamma \beta \tau_{u}}
$$

yields

$$
\phi\left(\frac{1+\gamma \tau_{u} a_{2}}{\gamma \beta \tau_{u}}\right)>0
$$

while evaluating it at

$$
a_{1}=\frac{2+3 \gamma \tau_{u} a_{2}}{2 \gamma \beta \tau_{u}}
$$

yields

$$
\phi\left(\frac{2+3 \gamma \tau_{u} a_{2}}{2 \gamma \beta \tau_{u}}\right)<0
$$

provided

$$
\begin{gathered}
\beta>\frac{1}{2} \\
\gamma^{2} \tau_{\epsilon} \tau_{u}>\frac{2(2 \beta-1)}{3-2 \beta} \\
\tau_{\eta} \leq \hat{\tau}_{\eta} \equiv \frac{(1 / 4 \beta-3 / 8) \gamma a_{2}^{3} \tau_{u}^{2}+1 / 2 a_{2}^{2} \tau_{u}(\beta-1 / 2)}{1+\gamma a_{2} \tau_{u}(3 / 2-\beta)} .
\end{gathered}
$$

Therefore, provided A.15a, A.15b) and A.15c are satisfied, a second equilibrium $a_{1}^{* *}$ 
exists in the interval

$$
\left(\frac{1+\gamma \tau_{u} a_{2}}{\gamma \beta \tau_{u}}, \frac{2+3 \gamma \tau_{u} a_{2}}{2 \gamma \beta \tau_{u}}\right)
$$

Given that $\phi(\cdot)$ is a quintic, it must have an odd number of roots, which implies that when A.15a, A.15b) and A.15c are satisfied at least another equilibrium $a_{1}^{* * *}$ must exist in the interval

$$
\left(\frac{2+3 \gamma \tau_{u} a_{2}}{2 \gamma \beta \tau_{u}}, \infty\right)
$$

Given the location of the roots we can conclude that $0<a_{1}^{*}<a_{2}<a_{1}^{* *}<a_{1}^{* * *}$. Furthermore, we have

$$
1+\gamma \tau_{u} \Delta a_{2}= \begin{cases}>0 & \text { for } a_{1}=a_{1}^{*} \\ <0 & \text { for } a_{1} \in\left\{a_{1}^{* *}, a_{1}^{* * *}\right\}\end{cases}
$$

which implies that $\lambda_{2}^{*}>0$, while $\lambda_{2}^{* *}<0$, and $\lambda_{2}^{* * *}<0$. Finally, we prove that price informativeness increases across the three equilibria. For $\tau_{1}$ this is immediate, since it increases in $a_{1}$. For $\tau_{2}$ as one can verify, given that $a_{1}^{*}<a_{2}<a_{1}^{* *}$ we have $\tau_{2}^{*}<\tau_{2}^{* *}$. Furthermore, for $a_{2}>\left(1+\gamma \tau_{u} a_{2}\right) /\left(\gamma \beta \tau_{u}\right)$,

$$
\frac{\partial \tau_{2}}{\partial a_{1}}>0
$$

which implies $\tau_{2}^{* *}<\tau_{2}^{* * *}$.

Suppose now that $\beta=0$. Then, $\phi(\cdot)$ becomes a cubic in $a_{1}$ :

$$
\begin{aligned}
\phi\left(a_{1}\right) & =a_{1}^{3} \tau_{u}\left(\left(1+\gamma a_{2} \tau_{u}\right)^{2}+\gamma^{2} \tau_{u} \tau_{\nu}\right)-a_{1}^{2} \gamma^{2} a_{2} \tau_{u}^{2}\left(a_{2}^{2} \tau_{u}+\tau_{\epsilon}+\tau_{\nu}\right) \\
& +a_{1}\left(3 a_{2} \tau_{u}\left(a_{2}\left(1+\gamma a_{2} \tau_{u}\right)+\gamma \tau_{\nu}\right)+\tau_{v}\left(\left(1+\gamma a_{2} \tau_{u}\right)^{2}+\gamma^{2} \tau_{\nu} \tau_{v}\right)+\tau_{\epsilon}+\gamma^{2} \tau_{u}\left(\tau_{\nu}+a_{2}^{2} \tau_{u}\right)^{2}\right) \\
& -\gamma^{2} a_{2} \tau_{u}\left(a_{2}^{2} \tau_{u}+\tau_{\epsilon}+\tau_{\nu}\right)\left(\tau_{v}+a_{2}^{2} \tau_{u}+\tau_{\epsilon}+\tau_{\nu}\right)
\end{aligned}
$$

with a negative discriminant. This implies that with $\beta=0$ there exists a unique equilibrium in linear strategies with first period responsiveness $a_{1}^{*}$. To locate the equilibrium, note that

$$
\begin{gathered}
\phi\left(\frac{\gamma^{2} a_{2} \tau_{u}\left(a_{2}^{2} \tau_{u}+\tau_{\epsilon}+\tau_{\nu}\right)}{1+\gamma^{2} \tau_{u}\left(a_{2}^{2} \tau_{u}+2 \tau_{\epsilon}+\tau_{\nu}\right)}\right)=-\frac{\gamma^{2} a_{2} \tau_{\nu} \tau_{u}\left(a_{2}^{2} \tau_{u}+\tau_{\epsilon}+\tau_{\nu}\right)}{1+\gamma^{2} \tau_{u}\left(a_{2}^{2} \tau_{u}+2 \tau_{\epsilon}+\tau_{\nu}\right)}<0 \\
\phi\left(a_{2}\right)=a_{2}\left(\tau_{v}+\tau_{\epsilon}\left(1+\gamma^{2} \tau_{u}\left(\tau_{\nu}+\tau_{\epsilon}\left(3+2 \gamma a_{2} \tau_{u}\right)+\tau_{v}\right)\right)\right)>0 .
\end{gathered}
$$


Therefore,

$$
a_{1}^{*} \in\left(\frac{\gamma^{2} a_{2} \tau_{u}\left(a_{2}^{2} \tau_{u}+\tau_{\epsilon}+\tau_{\nu}\right)}{1+\gamma^{2} \tau_{u}\left(a_{2}^{2} \tau_{u}+2 \tau_{\epsilon}+\tau_{\nu}\right)}, a_{2}\right) .
$$

Furthermore, since

$$
\psi^{\prime}\left(a_{1}\right) \propto 2 a_{1} \tau_{u}\left(\gamma^{2} a_{2} \tau_{u}\left(a_{2}^{2} \tau_{u}+\tau_{\epsilon}+\tau_{\nu}\right)-a_{1}\left(1+\gamma^{2} \tau_{u}\left(a_{2}^{2} \tau_{u}+2 \tau_{\epsilon}+\tau_{\nu}\right)\right),\right.
$$

we also have that for $\beta=0$, the weights to private information in the first period are strategic substitutes.

\section{Proof of Corollary 3}

For any $\beta \in[0,1]$, in the second period an equilibrium must satisfy $a_{2}=\gamma \tau_{\epsilon}$. In the first period, assuming $\tau_{\eta}=0$, and using A.10, at equilibrium $a_{1}$ equilibrium must satisfy

$$
\begin{aligned}
\phi_{1}\left(a_{1}\right) & \equiv a_{1} \lambda_{2}\left(\tau_{2}+\tau_{\epsilon}\right)-\gamma \tau_{\epsilon} \Delta a_{2} \tau_{u} \\
& =a_{1}\left(1+\gamma \tau_{u} \Delta a_{2}\right)-\gamma^{2} \tau_{\epsilon} \Delta a_{2} \tau_{u}=0 .
\end{aligned}
$$

The above equation is a quadratic in $a_{1}$ which for any $a_{2}>0$ and $\beta>0$ possesses two positive, real solutions:

$$
\begin{gathered}
a_{1}^{*}=\frac{1+\gamma \tau_{u} a_{2}(1+\beta)-\sqrt{\left(1+\gamma \tau_{u} a_{2}(1+\beta)\right)^{2}-4 \beta\left(\gamma \tau_{u} a_{2}\right)^{2}}}{2 \beta \gamma \tau_{u}} \\
a_{1}^{* *}=\frac{1+\gamma \tau_{u} a_{2}(1+\beta)+\sqrt{\left(1+\gamma \tau_{u} a_{2}(1+\beta)\right)^{2}-4 \beta\left(\gamma \tau_{u} a_{2}\right)^{2}}}{2 \beta \gamma \tau_{u}},
\end{gathered}
$$

with $a_{1}^{* *}>a_{1}^{*}$. This proves that for $\beta>0$ there are two linear equilibria.

Inspection of the above expressions for $a_{1}$ shows that $\beta a_{1}^{*}<a_{2}$, while $\beta a_{1}^{* *}>a_{2}$. The result for $\lambda_{2}, \operatorname{Var}_{1}\left[p_{2}\right]$ follows from substituting (A.19) and (A.20), respectively in $\lambda_{2}$ and $\operatorname{Var}_{1}\left[p_{2}\right]$. To see that prices are more informative along the HIE note that in the first period $\operatorname{Var}\left[v \mid z_{1}\right]^{-1}=\tau_{1}=\tau_{v}+a_{1}^{2} \tau_{u}$. In the second period, the price along the HIE is more informative than along the LIE if and only if

$$
\frac{\left(1+\beta^{2}+\gamma a_{2} \tau_{u}\left(\left(1-\beta^{2}\right)+\beta\left(1+\beta^{2}\right)\right)\right) \sqrt{\left(1+\gamma a_{2} \tau_{u}(1+\beta)\right)^{2}-4 \beta\left(\gamma a_{2} \tau_{u}\right)^{2}}}{\gamma^{2} \beta^{2} \tau_{u}}>0,
$$


which is always true. Given that $\tau_{i 2}=\tau_{2}+\tau_{\epsilon}$, this also implies that $\Lambda_{2}^{* * *}<\Lambda_{2}^{*}$. Finally, substitution of A.19 and A.20 in $\operatorname{Var}_{i 1}\left[p_{2}\right]$ shows that $\operatorname{Var}_{i 1}\left[p_{2}\right]^{* * *}<\operatorname{Var}_{i 1}\left[p_{2}\right]^{*}$. In view of (9) this implies that $\Lambda_{1}^{* * *}<\Lambda_{1}^{*}$.

When $\beta \rightarrow 0$, along the HIE we have

$$
\lim _{\beta \rightarrow 0} \frac{1+\gamma \tau_{u}\left(a_{2}+\beta \gamma \tau_{\epsilon}\right)+\sqrt{1+\gamma \tau_{u}\left(2\left(a_{2}+\beta \gamma \tau_{\epsilon}\right)+\gamma \tau_{u}\left(a_{2}-\beta \gamma \tau_{\epsilon}\right)^{2}\right)}}{2 \beta \gamma \tau_{u}}=\infty,
$$

while along the LIE, using l'Hospital's rule,

$$
\lim _{\beta \rightarrow 0} \frac{1+\gamma \tau_{u}\left(a_{2}+\beta \gamma \tau_{\epsilon}\right)-\sqrt{1+\gamma \tau_{u}\left(2\left(a_{2}+\beta \gamma \tau_{\epsilon}\right)+\gamma \tau_{u}\left(a_{2}-\beta \gamma \tau_{\epsilon}\right)^{2}\right)}}{2 \beta \gamma \tau_{u}}=\frac{\gamma a_{2}^{2} \tau_{u}}{1+\gamma a_{2} \tau_{u}} .
$$

From A.21 it then follows that in this case $\alpha_{P_{1}}<\alpha_{E_{1}}$. Finally, defining

$$
a_{10}^{*}=\frac{\gamma a_{2}^{2} \tau_{u}}{1+\gamma a_{2} \tau_{u}}
$$

and taking the limit of $\lambda_{2}$ as $\beta \rightarrow 0$ when $a_{1}=a_{10}^{*}$ yields

$$
\lim _{\beta \rightarrow 0} \lambda_{2}^{*}=\frac{1+\gamma \tau_{u} a_{2}}{\gamma\left(\tau_{v}+\left(a_{10}^{*}\right)^{2} \tau_{u}+a_{2}^{2} \tau_{u}+\tau_{\epsilon}\right)}>0
$$

whereas $\lim _{\beta \rightarrow 0} \lambda_{2}^{* * *}=0$.

\section{Proof of Corollary 4}

Starting from the LIE, we need to verify that $\left|\psi^{\prime}\left(a_{1}^{*}\right)\right|<1$, or that when $a_{1}=a_{1}^{*}$,

$$
\gamma \beta a_{2} \tau_{u}<\left(1+\gamma \tau_{u} \Delta a_{2}\right)^{2}
$$

Substituting A.19 on R.H.S. of the above inequality and rearranging yields

$$
\begin{aligned}
& \left|\psi^{\prime}\left(a_{1}^{*}\right)\right|<1 \Longleftrightarrow \\
& \quad-2\left(1+a_{2} \gamma \tau_{u}(1-\beta)\right)\left(1+a_{2} \gamma \tau_{u}(1-\beta)+\sqrt{\left(1+\gamma \tau_{u} a_{2}(1+\beta)\right)^{2}-4 \beta\left(\gamma \tau_{u} a_{2}\right)^{2}}\right)<0,
\end{aligned}
$$

which is always satisfied. For the HIE, we need instead to verify that $\left|\psi^{\prime}\left(a_{1}^{* * *}\right)\right|>1$, or that when $a_{1}=a_{1}^{* * *}$,

$$
\gamma \beta a_{2} \tau_{u}>\left(1+\gamma \tau_{u} \Delta a_{2}\right)^{2} .
$$


Substituting (A.20) on R.H.S. of the above inequality and rearranging yields

$$
\begin{aligned}
& \left|\psi^{\prime}\left(a_{1}^{* * *}\right)\right|>1 \Longleftrightarrow \\
& \quad 2\left(1+a_{2} \gamma \tau_{u}(1-\beta)\right)\left(-\left(1+a_{2} \gamma \tau_{u}(1-\beta)\right)+\sqrt{\left(1+\gamma \tau_{u} a_{2}(1+\beta)\right)^{2}-4 \beta\left(\gamma \tau_{u} a_{2}\right)^{2}}\right)>0,
\end{aligned}
$$

which is always satisfied, since the first factor in the product on the R.H.S. of the above expression is positive, while manipulating the second factor shows that

$$
\sqrt{\left(1+\gamma \tau_{u} a_{2}(1+\beta)\right)^{2}-4 \beta\left(\gamma \tau_{u} a_{2}\right)^{2}}>\left(1+a_{2} \gamma \tau_{u}(1-\beta)\right) \Longleftrightarrow 4 a_{2} \beta \gamma \tau_{u}>0
$$

\section{Proof of Corollary 5}

In the second period, the result follows from the fact that since at equilibrium $a_{2}=\gamma \tau_{\epsilon}$,

$$
\frac{a_{2}}{\alpha_{E_{2}}}=\frac{\gamma}{\operatorname{Var}_{i 2}[v]}
$$

In period 1 we have

$$
X_{1}\left(s_{i}, z_{1}\right)=\gamma \frac{\left(\lambda_{2} \Delta a_{2}+\tau_{\eta} / \tau_{i 2}\right) E_{i 1}[v]}{\operatorname{Var}_{i 1}\left[p_{2}\right]}+\frac{\gamma}{\operatorname{Var}_{i 1}\left[p_{2}\right]}\left(\frac{\beta \alpha_{P_{2}}}{a_{2}} z_{1}+\left(1-\alpha_{P_{2}}\right) \frac{\tau_{1}}{\tau_{2}} E_{1}[v]\right)-\frac{\gamma}{\operatorname{Var}_{i 1}\left[p_{2}\right]} p_{1} .
$$

Adding and subtracting $\left(a_{1} / \alpha_{E_{1}}\right) p_{1}$ from the right hand side of the above expression yields

$$
X_{1}\left(s_{i}, z_{1}\right)=\frac{a_{1}}{\alpha_{E_{1}}}\left(E_{i 1}[v]-p_{1}\right)+\left(\frac{a_{1}}{\alpha_{E_{1}}}-\frac{\gamma}{\operatorname{Var}_{i 1}\left[p_{2}\right]}\right) p_{1}+\frac{\gamma}{\operatorname{Var}_{i 1}\left[p_{2}\right]}\left(\frac{\beta}{\gamma \tau_{i 2}} z_{1}+\frac{\tau_{1}}{\tau_{i 2}} E_{1}[v]\right) .
$$

The second and third terms in the above expression can be rewritten to obtain

$$
\begin{aligned}
\left(\frac{a_{1}}{\alpha_{E_{1}}}-\frac{\gamma}{\operatorname{Var}_{i 1}\left[p_{2}\right]}\right) p_{1}+\frac{\gamma}{\operatorname{Var}_{i 1}\left[p_{2}\right]}\left(\frac{\beta}{\gamma \tau_{i 2}} z_{1}+\frac{\tau_{1}}{\tau_{i 2}} E_{1}[v]\right) & =\frac{\beta\left(1-\alpha_{P_{1}}\right)-\gamma \tau_{1} \alpha_{P_{1}}}{a_{1} \tau_{i 2} \operatorname{Var}_{i 1}\left[p_{2}\right]} E_{1}\left[\theta_{1}\right] \\
& =\frac{\alpha_{P_{1}}-\alpha_{E_{1}}}{\alpha_{E_{1}}} E_{1}\left[\theta_{1}\right] .
\end{aligned}
$$

Note, also, that setting $\rho \equiv a_{1} / a_{2}$, we can express

$$
\alpha_{P_{1}}=\alpha_{E_{1}}\left(1+\frac{(\beta \rho-1) \tau_{1}}{\tau_{i 2}}\right)
$$


This implies that for $a_{1}=a_{1}^{*}, \alpha_{P_{1}}<\alpha_{E_{1}}$, whereas the opposite holds for $a_{1} \in\left\{a_{1}^{* *}, a_{1}^{* * *}\right\}$. To differentiate $x_{i 2}$ with respect to $p_{2}$, we first express the information contained in a trader's forecast in terms of $p_{2}$. To this end we use A.6 and write

$$
z_{2}=\frac{1}{\lambda_{2}}\left(p_{2}-\frac{\tau_{\eta}}{\tau_{i 2}} s_{P}-\frac{\beta \alpha_{P_{2}}}{a_{2}} z_{1}-\left(1-\alpha_{P_{2}}\right) \frac{\tau_{1}}{\tau_{2}} E_{1}[v]\right)
$$

Substituting the above in $E_{i 2}[v]$, and differentiating $x_{i 2}$ with respect to $p_{2}$ yields

$$
\frac{\partial x_{i 2}}{\partial p_{2}}=-\frac{\gamma \tau_{i 2}}{1+\gamma \tau_{u} \Delta a_{2}}
$$

For $a_{1}=a_{1}^{*}$, we know that $\Delta a_{2}>0$, so that the information effect reinforces the substitution effect and the asset is a normal good. Conversely, when multiple equilibria arise, for $a_{1} \in\left\{a_{1}^{* *}, a_{1}^{* * *}\right\}, 1+\gamma \tau_{u} \Delta a_{2}<0$, implying that the asset is a Giffen good.

Finally, to compute the conditional covariance we have

$$
\begin{aligned}
\operatorname{Cov}_{i 1}\left[v-p_{2}, p_{2}-p_{1}\right] & =\operatorname{Cov}_{i 1}\left[v-p_{2}, p_{2}\right] \\
& =\operatorname{Cov}_{i 1}\left[v, p_{2}\right]-\operatorname{Var}_{i 1}\left[p_{2}\right] .
\end{aligned}
$$

Using (10b), we obtain

$$
\operatorname{Cov}_{i 1}\left[v, p_{2}\right]=\frac{1}{\tau_{i 1}}\left(\lambda_{2} \Delta a_{2}+\frac{\tau_{\eta}}{\tau_{i 1}}\right)
$$

On the other hand, from A.13 we have

$$
\operatorname{Var}_{i 1}\left[p_{2}\right]=\frac{1}{\tau_{i 1}}\left(\lambda_{2} \Delta a_{2}+\frac{\tau_{\eta}}{\tau_{i 2}}\right)^{2}+\frac{\lambda_{2}^{2}}{\tau_{u}}+\frac{\tau_{\eta}}{\tau_{i 2}^{2}} .
$$

Substituting these expressions in A.22 and rearranging yields

$$
\operatorname{Cov}_{i 1}\left[v-p_{2}, p_{2}-p_{1}\right]=-\frac{1}{\gamma \tau_{i 1} \tau_{i 2}}\left(\frac{\lambda_{2}\left(\tau_{i 2}-\tau_{\eta}\right)}{\tau_{u}}+\frac{\Delta a_{2} \tau_{\eta}}{\tau_{i 2}}\right)
$$

According to Proposition 2, when $a_{1} \in\left\{a_{1}^{* *}, a_{1}^{* * *}\right\}, \Delta a_{2}<0$ and $\lambda_{2}<0$. Therefore, $\operatorname{Cov}_{i 1}\left[v-p_{2}, p_{2}-p_{1}\right]>0$. Conversely, along the LIE, the opposite occurs. 


\section{Proof of Corollary 6}

We have already established in Corollary 5 that along the HIE (LIE) $\alpha_{P_{1}}>\alpha_{E_{1}}\left(\alpha_{P_{1}}<\right.$ $\left.\alpha_{E_{1}}\right)$. Now, using (6) the covariance between $p_{1}$ and $v$ is given by

$$
\operatorname{Cov}\left[v, p_{1}\right]=\alpha_{P_{1}} \frac{1}{\tau_{v}}+\left(1-\alpha_{P_{1}}\right)\left(\frac{1}{\tau_{v}}-\frac{1}{\tau_{1}}\right)
$$

and carrying out a similar computation for the first period consensus opinion

$$
\operatorname{Cov}\left[\bar{E}_{1}[v], v\right]=\alpha_{E_{1}} \frac{1}{\tau_{v}}+\left(1-\alpha_{E_{1}}\right)\left(\frac{1}{\tau_{v}}-\frac{1}{\tau_{1}}\right) .
$$

We can now subtract A.24 from A.23 and obtain

$$
\operatorname{Cov}\left[p_{1}-\bar{E}_{1}[v], v\right]=\frac{\alpha_{P_{1}}-\alpha_{E_{1}}}{\tau_{1}}
$$

implying that the price at time 1 over relies on public information (compared to the optimal statistical weight) if and only if the covariance between the price and the fundamentals falls short of that between the consensus opinion and the fundamentals.

\section{$\underline{\text { Proof of COROllary } 7}$}

To compute $\operatorname{Cov}\left[p_{2}-p_{1}, p_{1}-\bar{v}\right]$ we first note that

$$
\operatorname{Cov}\left[p_{2}-p_{1}, p_{1}-\bar{v}\right]=\operatorname{Cov}\left[p_{2}, p_{1}\right]-\operatorname{Var}\left[p_{1}\right]
$$

Next,

$$
\operatorname{Cov}\left[p_{2}, p_{1}\right]=\operatorname{Cov}\left[E_{1}\left[p_{2}\right], E_{1}\left[p_{1}\right]\right]+\operatorname{Cov}_{1}\left[p_{2}, p_{1}\right]=\operatorname{Cov}\left[E_{1}\left[p_{2}\right], p_{1}\right]
$$

Computing

$$
\begin{aligned}
\operatorname{Cov}\left[E_{1}\left[p_{2}\right], p_{1}\right] & =\operatorname{Var}\left[E_{1}[v]\right]+\left(\Lambda_{1}+\beta \Lambda_{2}\right) \operatorname{Cov}\left[E_{1}[v], E_{1}\left[\theta_{1}\right]\right]+\beta \Lambda_{2} \Lambda_{1} \operatorname{Var}\left[E_{1}\left[\theta_{1}\right]\right] \\
& =\frac{a_{1}^{2} \tau_{1}}{\tau_{1} \tau_{v}}+\left(\Lambda_{1}+\beta \Lambda_{2}\right) \frac{a_{1}}{\tau_{1}}+\beta \Lambda_{2} \Lambda_{1} \frac{\tau_{v}}{\tau_{1} \tau_{u}}
\end{aligned}
$$

and

$$
\operatorname{Var}\left[p_{1}\right]=\frac{a_{1}^{2} \tau_{u}}{\tau_{1} \tau_{v}}+\Lambda_{1}^{2} \frac{\tau_{v}}{\tau_{1} \tau_{u}}+2 \Lambda_{1} \frac{a_{1}}{\tau_{1}}
$$


Substituting these expressions in A.26 and rearranging yields

$$
\operatorname{Cov}\left[p_{2}-p_{1}, p_{1}-\bar{v}\right]=-\frac{\operatorname{Var}_{i 1}\left[p_{2}\right]}{\gamma}\left(\Lambda_{1} \frac{\tau_{v}}{\tau_{1} \tau_{u}}+\frac{a_{1}}{\tau_{1}}\right)<0
$$

Consider now $\operatorname{Cov}\left[v-p_{2}, p_{1}-\bar{v}\right]$, decomposing the covariance yields

$$
\begin{aligned}
\operatorname{Cov}\left[v-p_{2}, p_{1}-\bar{v}\right] & =\operatorname{Cov}\left[E_{1}\left[v-p_{2}\right], p_{1}\right]+\underbrace{\operatorname{Cov}_{1}\left[v-p_{2}, p_{1}-\bar{v}\right]}_{=0} \\
& =-\beta \Lambda_{2}\left(\operatorname{Cov}\left[E_{1}\left[\theta_{1}\right], E_{1}[v]\right]+\Lambda_{1} \operatorname{Var}\left[E_{1}\left[\theta_{1}\right]\right]\right) \\
& =-\beta \Lambda_{2}\left(\frac{a_{1}}{\tau_{1}}+\Lambda_{1} \frac{\tau_{v}}{\tau_{1} \tau_{u}}\right) \\
& =-\beta \Lambda_{2} \lambda_{1} \frac{1}{\tau_{u}},
\end{aligned}
$$

which is always negative for $\beta \in(0,1]$, and null for $\beta=0$. Finally, to compute $\operatorname{Cov}[v-$ $\left.p_{2}, p_{2}-p_{1}\right]$ we decompose again the covariance

$$
\operatorname{Cov}\left[v-p_{2}, p_{2}-p_{1}\right]=\operatorname{Cov}\left[E_{1}\left[v-p_{2}\right], E_{1}\left[p_{2}-p_{1}\right]\right]+\operatorname{Cov}_{1}\left[v-p_{2}, p_{2}-p_{1}\right]
$$

Computing, $E_{1}\left[v-p_{2}\right]=-\beta \Lambda_{2} E_{1}\left[\theta_{1}\right]$, and $E_{1}\left[p_{2}-p_{1}\right]=\left(\beta \Lambda_{2}-\Lambda_{1}\right) E_{1}\left[\theta_{1}\right]$. Therefore,

$$
\operatorname{Cov}\left[E_{1}\left[v-p_{2}\right], E_{1}\left[p_{2}-p_{1}\right]\right]=\beta \Lambda_{2} \frac{\operatorname{Var}_{i 1}\left[p_{2}\right]}{\gamma} \operatorname{Var}\left[E_{1}\left[\theta_{1}\right]\right]
$$

Next, we obtain

$$
\operatorname{Cov}_{1}\left[v-p_{2}, p_{2}-p_{1}\right]=\frac{\left(1+\gamma \tau_{u} \Delta a_{2}\right)\left(\beta a_{1} \Delta a_{2} \tau_{u}-\tau_{1}\right)+\gamma \tau_{\eta} \tau_{u} \beta a_{1}}{\left(\gamma \tau_{i 2}\right)^{2} \tau_{1} \tau_{u}}
$$

When $a_{1} \in\left\{a_{1}^{* *}, a_{1}^{* * *}\right\}, \Delta a_{2}<-\left(\gamma \tau_{u}\right)^{-1}$, and the above expression is always positive, which implies that along the $\operatorname{HIE} \operatorname{Cov}\left[v-p_{2}, p_{2}-p_{1}\right]>0$.

\section{Proof of Corollary 8}

To prove this result, we impose $\tau_{\eta}=0$ in A.27 and A.28, obtaining

$$
\operatorname{Cov}\left[v-p_{2}, p_{2}-p_{1}\right]=-\frac{\lambda_{2}}{\gamma \tau_{i 2} \tau_{u}}\left(1-\beta \Delta a_{2} \frac{\tau_{i 1}-\tau_{v}}{a_{1} \tau_{i 1}}\right)
$$

Looking at A.29) we again verify that along the HIE there is momentum. This is true 
because in that equilibrium $\lambda_{2}<0$ and $\Delta a_{2}<0$. Along the LIE momentum can occur, depending on the persistence of liquidity trades. To see this, note that since in this equilibrium $\lambda_{2}>0$ and $\Delta a_{2}>0$, from A.29 momentum needs

$$
1-\beta \Delta a_{2} \frac{\tau_{i 1}-\tau_{v}}{a_{1} \tau_{i 1}}<0
$$

which can be rearranged as an (implicit) condition on the magnitude of $\beta$ :

$$
\frac{a_{1} \tau_{i 1}}{\Delta a_{2}\left(\tau_{i 1}-\tau_{v}\right)}<\beta<1
$$

If $\beta=0$, the above condition is never satisfied. Indeed, in this case there exists a unique equilibrium in which $\Delta a_{2}=a_{2}>0$. Therefore, when $\beta=0$ returns always display reversal. If $\beta=1$, the condition is satisfied if

$$
a_{1} \tau_{v}+a_{1}\left(\tau_{\epsilon}+a_{1}^{2} \tau_{u}\right)<\Delta a_{2} \tau_{u}\left(\tau_{\epsilon}+a_{1}^{2} \tau_{u}\right)
$$

Isolating $\tau_{v}$ in the above expression yields:

$$
\tau_{v}<\hat{\tau}_{v} \equiv \frac{\left(\Delta a_{2}-a_{1}\right)\left(\tau_{\epsilon}+a_{1}^{2} \tau_{u}\right)}{a_{1}},
$$

which, since $a_{1}$ does not depend on $\tau_{v}$ (see A.19), gives an explicit upper bound on $\tau_{v}$. Hence, if $\tau_{v}<\hat{\tau}_{v}$, there exists a $\hat{\beta}$ such that for all $\beta \geq \hat{\beta}$, when $\tau_{\eta}=0$, momentum occurs between the second and third period returns along the LIE. 